\title{
Validation of ECMWF and NCEP-NCAR Reanalysis Data in Antarctica
}

\author{
YU Lejiang ${ }^{1}$ (于乐江), ZHANG Zhanhai ${ }^{1}$ (张占海), ZHOU Mingyu*1 (周明显), Shiyuan ZHONG ${ }^{2}$, \\ Donald LENSCHOW ${ }^{3}$, Hsiaoming $\mathrm{HSU}^{3}$, WU Huiding ${ }^{4}$ (吴辉碇), and $\mathrm{SUN} \mathrm{Bo}^{1}$ (孙波) \\ ${ }^{1}$ Polar Research Institute of China, Shanghai 200136 \\ ${ }^{2}$ Department of Geography, Michigan State University, East Lansing, MI 48824-111, USA \\ ${ }^{3}$ National Center for Atmospheric Research, Boulder, CO 80307, USA \\ ${ }^{4}$ National Marine Environmental Forecast Center, Beijing 100081
}

(Received 8 September 2009; revised 18 December 2009)

\begin{abstract}
The European Center for Medium-Range Weather Forecast (ECMWF) Re-Analysis (ERA-40) and the National Centers for Environmental Prediction-National Center for Atmospheric Research (NCEP-NCAR) ECMWF (ERA-40) and NCEP-NCAR reanalysis data were compared with Antarctic station observations, including surface-layer and upper-layer atmospheric observations, on intraseasonal and interannual timescales. At the interannual timescale, atmospheric pressure at different height levels in the ERA- 40 data are in better agreement with observed pressure than that in the NCEP-NCAR reanalysis data. ERA-40 reanalysis also outperforms NCEP-NCAR reanalysis in atmospheric temperature, except in the surface layer where the biases are somewhat larger. The wind velocity fields in both datasets do not agree well with surface- and upper-layer atmospheric observations. At intraseasonal timescales, both datasets capture the observed intraseasonal variability in pressure and temperature during austral winter.
\end{abstract}

Key words: reanalysis data, interannual variability, intraseasonal variability, surface layer, upper layer, Antarctica

Citation: Yu, L., Z. Zhang, M. Zhou, S. Zhong, D. Lenschow, H. Hsu, H. Wu, and B. Sun, 2010: Validation of ECMWF and NCEP-NCAR reanalysis data in Antarctica. Adv. Atmos. Sci., 27(5), 1151-1168, doi: $10.1007 / \mathrm{s} 00376-010-9140-1$.

\section{Introduction}

Meteorological observations in Antarctica are sparse, especially in the interior of the continent. Studies of the weather and climate of the Antarctic often rely upon the outputs from various global or regional atmospheric numerical models and gridded global reanalysis datasets derived from both models and observations, such as the ECMWF dataset (ERA-40) (Uppala et al., 2005) or that of the NCEP-NCAR European Center for Medium-Range Weather Forecast (ECMWF) Re-Analysis (ERA-40) (Uppala et al., 2005) and the National Centers for Environmental Prediction (NCEP)-National Center for Atmospheric Research (NCAR) global reanalysis (Kalnay et al.,
1996; Kistler et al., 2001). Given the importance of these gridded datasets in understanding the weather and climate over Antarctica, it is necessary to verify whether they do in fact represent the true state of the atmosphere over Antarctica, rather than simply the idiosyncracies of the models used to produce them.

A number of studies have evaluated these reanalysis datasets using surface and upper-level observations in Antarctica. Using observations from the Antarctic First Regional Observing Study of the Troposphere (FROST) in 1994-1995, Bromwich and Smith (1993), Turner et al. (1996), and Turner et al. (1999) found that the NCEP-NCAR and ECMWF reanalysis are able to produce the main circulation features over Antarctica, despite some minor discrepancies in the

\footnotetext{
*Corresponding author: ZHOU Mingyu, mingyuzhou@yahoo.com

(C) China National Committee for International Association of Meteorology and Atmospheric Sciences (IAMAS), Institute of Atmospheric Physics (IAP) and Science Press and Springer-Verlag Berlin Heidelberg 2010
} 
depths and locations of the lows. Cullather et al. (1997) compared the two reanalysis products for a 10yr (1985-1995) period and found that surface pressure in the two reanalysis datasets is in better agreement with observations than surface air temperature and wind, and that the errors in both reanalysis at the standard pressure levels decrease with time. Bromwich et al. (1995) found that the ECMWF reanalysis data are superior to those of the $\mathrm{NCEP}-\mathrm{NCAR}$ in reproducing the atmospheric moisture budget in high southern latitudes for the period 1985-1992. Bromwich et al. (1999) verified NCEP reanalysis data against FROST data and showed that the reanalysis produces warmer surface temperatures and weaker near-surface temperature inversions. Connolley and Harangozo (2001) also found poor agreement between observed near-surface temperatures and those from both the NCEP and ECMWF reanalysis. King (2003) used surface pressure data derived from instruments deployed on ice floes in southern Bellingshausen to assess ECMWF reanalysis data for February-May 2001. King found that the analyses agree well with observed pressure and pressure gradients. Hines et al. (2000) and Marshall (2002) noted some spurious trends in air temperature and geopotential height at different levels in the NCEP-NCAR reanalysis data. In several studies on the Antarctic Oscillation and East Asian climate (Fan and Wang, 2004; Sun et al., 2008; Yue and Wang, 2008; Zhu, 2009), the NCEP-NCAR reanalysis data were compared against those of the ECMWF reanalysis data and good agreement was demonstrated.

These previous studies have helped those working in this field to understand the strengths and weaknesses of global reanalysis products over Antarctica, and therefore their usefulness in improving our understanding of weather and climate in this important and yet data-sparse region. Most of these studies, however, have limited their comparisons to a short time period, or the surface only, or a single height pressure level aloft, and standard statistics.

In this study, the ERA-40 and NCEP-NCAR (II) reanalysis datasets were evaluated using surface-layer and upper-layer observational data over a 29-yr period (1979-2008). The evaluations were not limited to surface-layer variables, but variables at multiple height pressure levels aloft in order to understand whether the reanalysis datasets capture the vertical structure and variation. Further, in addition to using standard comparison statistics, spectral properties and major Empirical Orthogonal Function (EOF) modes have also been compared in order to understand the ability of the reanalysis data in capturing interannual and intraseasonal variability and the spatial patterns of the variability.
This paper is organized as follows. Data and the analysis methods are described in section 2 . The validation results of the two reanalysis datasets are presented in section 3 , followed by discussion in section 4 . Conclusions are drawn in section 5 .

\section{Data and methodology}

\subsection{Reanalysis datasets}

This study evaluates two global datasets: the NCEP-NCAR global reanalysis and the ERA-40 reanalysis. These long-term, dynamically consistent global datasets are produced using a global data assimilation system with inputs from atmospheric global model outputs and various observations from multiple sources, including radiosondes, satellites, ships, and aircraft. The datasets consist of a large set of atmospheric and hydrological variables at the surface and multiple levels throughout the atmosphere, at multiple times per day on a global grid.

The NCEP-NCAR global reanalysis is based on the NCEP operational Eta model of 10 January 1995 with a reduced horizontal resolution of T42 $(209 \mathrm{~km})$ and 28 vertical levels. Its temporal coverage is four times per day from 1 January 1948 to the present day for the first reanalysis (NCEP I) and for NCEP II from 1 January 1979 to the present day for the second reanalysis (NCEP II). Satellite sounder data were first assimilated into the NCEP-NCAR reanalysis in March 1975 (Jenne, 2000). From 1979 onwards, data from the Television Infrared Observational Satellite (TIROS) Operational Vertical Sounder (TOVS) data started to constrain the NCEP reanalysis (Kistler and Kalnay, 2000). A potential problem for the current study was that the Australian Surface Pressure Bogus Data for the Southern Hemisphere south of $40^{\circ} \mathrm{S}$ were read with a $180^{\circ}$ error in longitude between 1979 and 1992 (Kistler et al., 2001). This error had its greatest effect between $45^{\circ}$ and $60^{\circ} \mathrm{S}$ and the effect decreases toward the South Pole. It is possible that this would affect the comparisons at intraseasonal timescales. Detailed descriptions of the NCEP-NCAR global reanalysis data are given by Kalnay et al. (1996), Kistler et al. (2001), and Kanamitsu et al. (2002).

In this study, the NCEP-DOE (Department of Energy) Reanalysis II dataset, an improved version of NCEP Reanalysis I having fixed errors and updated parameterizations of physical processes (Kanamitsu et al., 2002), was used for the evaluation. NCEP II fixed the Southern Hemisphere bogus (PAOBS), which can contaminate some day-to-day analyses of the extratropical regions of the Southern Hemisphere. The albedo error over the ocean in NCEP I is also corrected in NCEP II. More details on the corrected er- 
rors and improvements are presented in Kanamitsu et al. (2002).

The ERA-40 reanalysis contains data from September 1957 to August 2002 with a horizontal resolution of T159 (125 km) and 60 vertical levels (23 standard pressure levels). IFS CY23r4 is used as the atmospheric model for ERA-40. A comprehensive documentation of the ECMWF forecasting system can be found on the ECMWF website at http:// www.ecmwf.int/research/ifsdocs/CY23r4/index.html. From the beginning of the run, ERA-40 assimilated much observational data from Antarctic stations that were not assimilated into NCEP I until the Global Telecommunications System (GTS) data were made available. Observational data available for ERA-40 are those from the Automatic Meteorological stations data from University of Wisconsin (1980-1998), the Antarctic surface dataset from the British Antarctic Survey (1950-1999), and the Australian Antarctic surface and radiosonde dataset from the Australian Bureau of Meteorology National Climate Centre (19471999) (Kallberg et al., 2004). ERA-40 is a secondgeneration reanalysis with its predecessor (ERA-15) covering 1979-1993 (Gibson et al., 1997). In this paper, owing to the TOVS data introduced into ERA-40 in 1979, the validation was made from 1979 to 2001 . More descriptions of ERA-40 can be found in Uppala et al. (2005).

Although the two global reanalysis are based on models with different horizontal and vertical resolutions, the outputs of the models are archived on a $2.5^{\circ} \times 2.5^{\circ}$ global latitude and longitude grid with 23 vertical pressure levels and a temporal resolution of 6 hrs. NCEP II and ERA-40 reanalysis use 3D variational assimilation (3D VAR) schemes. For NCEP II primary sea ice data are obtained from the Scanning Multichannel Microwave Radiometer (SMMR) and Special Sensor Microwave/Imager (SSM/I); for ERA40 these are derived from the Hadley Centre Global Sea Ice Cover and SST data version 1 (HADISST1) from 1957 to 1981 and the Reynolds optimally interpolated sea ice concentration (Reynolds OI) from 1982 to 2002. Snow cover data used for NCEP II and ERA40 are from the National Environmental Satellite Data and Information Service weekly analyses and the climatology of snow cover (NESDIS) and synoptic reports of snow depth (SYNOP), respectively. These differences in the two reanalysis may result in different outputs over Antarctica.

\subsection{Observational data}

The above reanalysis datasets are evaluated using observations from nine surface weather stations and four radiosonde sites at various locations in Antarc-

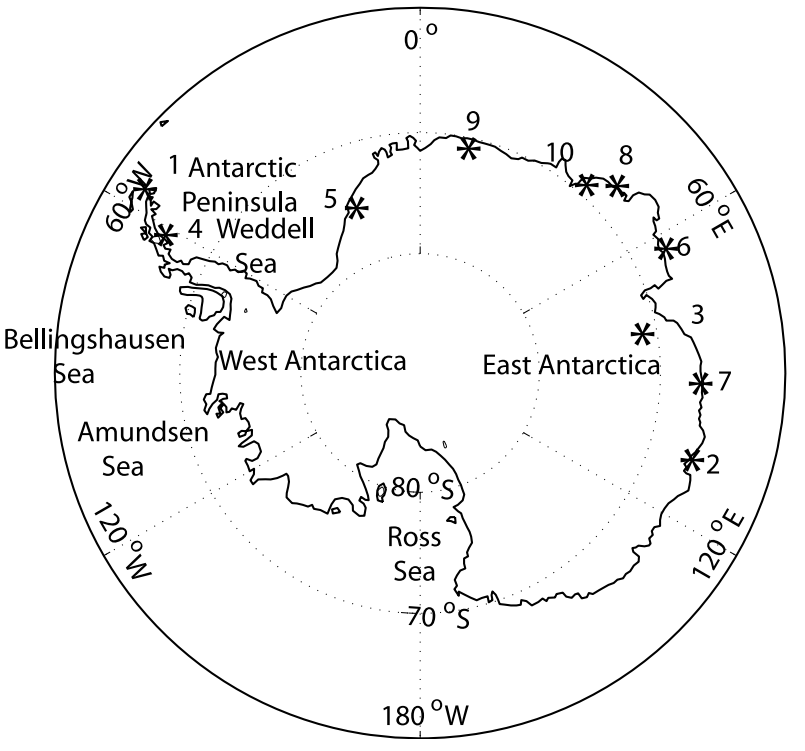

Fig. 1. Locations of the stations listed in Table 1.

tica. These (both surface and upper air) data are obtained from the British Antarctic Survey READER project (http://www.antarctic.ac.uk/met/READER/). The locations of the stations, together with the topography of Antarctica, are shown in Fig. 1. Table 1 provides geographic information for the observational sites, as well as information on the data records. These stations, most of which are in East Antarctica and all of which are in coastal areas, were chosen for the study because of their completeness and longevity of data. Data from the surface stations are recorded four times per day and the lengths of daily records vary significantly among the stations, ranging from 37 years at Molodeznaja station to 61 years at Faraday station. The data quality is generally very good, with missing or bad records ranging from $0.1 \%$ at Bellingshausen to $17.2 \%$ at Syowa (Table 1). The sounding data are available twice a day and the lengths of the data records vary among the four stations, from a minimum of 49 years (1957-2005) at Syowa to a maximum of 51 years (1956-2006) at Mirny. Some of these sounding data have been assimilated into both reanalysis datasets, so they are not considered as independent for comparison purposes. The results of comparisons will, however, still be valuable because they will provide a best case scenario.

In this study, due to the difference in length of the two reanalysis, and because the focus of the comparison is intraseasonal and interannual variation, the daily and monthly mean data from 1979 to 2001 are used. The comparison with the sounding data was limited to nine standard pressure levels above ground (850, 700, 500, 300, 200, 150, 100, 50 and $30 \mathrm{hPa})$. 
Table 1. Coordinates of all stations in the study. No. refers to the number above the plotted stations in Fig. 1. The validated variables are surface sea level pressure $(*)$, surface air temperature $(\#)$, surface wind velocity (\%) and upper-air variables $(\$)$. Latitude, longitude, altitude, total coverage period and total record number are also included.

\begin{tabular}{|c|c|c|c|c|c|c|c|c|}
\hline \multirow[t]{2}{*}{ No. } & \multirow{2}{*}{$\begin{array}{l}\text { Station } \\
\text { name }\end{array}$} & \multirow[t]{2}{*}{ Latitude } & \multirow[t]{2}{*}{ Longitude } & \multirow{2}{*}{$\begin{array}{l}\text { Altitude } \\
\text { (m) }\end{array}$} & \multirow{2}{*}{$\begin{array}{l}\text { Variable of } \\
\text { validation }\end{array}$} & \multicolumn{3}{|c|}{ Total coverage period and total record number } \\
\hline & & & & & & Pressure & Temperature & Wind speed \\
\hline$\overline{1}$ & $\begin{array}{l}\text { Bellingsh- } \\
\text { ausen }\end{array}$ & $62.2^{\circ} \mathrm{S}$ & $58.9^{\circ} \mathrm{W}$ & 16 & $* \#$ & $\begin{array}{l}\text { 1/Mar/1968 } \\
1 / \mathrm{Nov} / 2006 \\
56499\end{array}$ & $\begin{array}{l}\text { 1/Mar/1968 } \\
1 / \mathrm{Nov} / 2006 \\
56499\end{array}$ & $\begin{array}{l}\text { 1/Mar/1968 } \\
1 / \mathrm{Nov} / 2006 \\
56499\end{array}$ \\
\hline 2 & Casey & $66.3^{\circ} \mathrm{S}$ & $110.5^{\circ} \mathrm{E}$ & 42 & * \# \% & $\begin{array}{l}31 / \operatorname{Jan} / 1959 \\
31 / \mathrm{Dec} / 2005 \\
68334\end{array}$ & $\begin{array}{l}31 / \operatorname{Jan} / 1959 \\
31 / \mathrm{Dec} / 2005 \\
68334\end{array}$ & $\begin{array}{l}1 / \mathrm{Feb} / 1960 \\
31 / \mathrm{Dec} / 2005 \\
66895\end{array}$ \\
\hline 3 & Davis & $68.6^{\circ} \mathrm{S}$ & $78.0^{\circ} \mathrm{E}$ & 13 & $* \# \%$ & $\begin{array}{l}10 / \mathrm{Feb} / 1957 \\
31 / \mathrm{Dec} / 2005 \\
65054\end{array}$ & $\begin{array}{l}10 / \mathrm{Feb} / 1957 \\
31 / \mathrm{Dec} / 2005 \\
65054\end{array}$ & $\begin{array}{l}\text { 10/Feb/1957 } \\
31 / \mathrm{Dec} / 2005 \\
65054\end{array}$ \\
\hline 4 & Faraday & $65.4^{\circ} \mathrm{S}$ & $64.4^{\circ} \mathrm{W}$ & 11 & $* \# \%$ & $\begin{array}{l}\text { 15/Jan/1947 } \\
28 / \mathrm{Feb} / 2007 \\
86807\end{array}$ & $\begin{array}{l}\text { 15/Jan/1947 } \\
28 / \mathrm{Feb} / 2007 \\
86807\end{array}$ & $\begin{array}{l}\text { 31/Mar/1950 } \\
28 / \mathrm{Feb} / 2007 \\
83544\end{array}$ \\
\hline 5 & Halley & $75.5^{\circ} \mathrm{S}$ & $26.4^{\circ} \mathrm{W}$ & 30 & $\% \$$ & $\begin{array}{l}\text { 1/Jan/1957 } \\
9 / \mathrm{Aug} / 2007 \\
73864\end{array}$ & $\begin{array}{l}\text { 1/Jan/1957 } \\
9 / \mathrm{Aug} / 2007 \\
73864\end{array}$ & $\begin{array}{l}\text { 1/Jan/1957 } \\
9 / \mathrm{Aug} / 2007 \\
73864\end{array}$ \\
\hline 6 & Mawson & $67.6^{\circ} \mathrm{S}$ & $62.9^{\circ} \mathrm{E}$ & 16 & $* \# \%$ & $\begin{array}{l}23 / \mathrm{Feb} / 1954 \\
31 / \mathrm{Dec} / 2005 \\
75723\end{array}$ & $\begin{array}{l}23 / \mathrm{Feb} / 1954 \\
31 / \mathrm{Dec} / 2005 \\
75723\end{array}$ & $\begin{array}{l}23 / \mathrm{Feb} / 1954 \\
31 / \mathrm{Dec} / 2005 \\
75684\end{array}$ \\
\hline 7 & Mirny & $66.5^{\circ} \mathrm{S}$ & $93.0^{\circ} \mathrm{E}$ & 30 & $\$$ & $\begin{array}{l}1 / \text { Feb/1956 } \\
31 / \text { Oct/2006 } \\
73291\end{array}$ & $\begin{array}{l}\text { 1/Feb/1956 } \\
31 / \text { Oct/2006 } \\
73291\end{array}$ & $\begin{array}{l}1 / \text { Feb/1956 } \\
31 / \text { Oct/2006 } \\
73290\end{array}$ \\
\hline 8 & $\begin{array}{l}\text { Molodez- } \\
\text { naja }\end{array}$ & $67.7^{\circ} \mathrm{S}$ & $45.9^{\circ} \mathrm{E}$ & 40 & * \# & $\begin{array}{l}\text { 1/Mar/1963 } \\
\text { 30/Jun/1999 } \\
53053\end{array}$ & $\begin{array}{l}\text { 1/Mar/1963 } \\
\text { 30/Jun/1999 } \\
53053\end{array}$ & $\begin{array}{l}\text { 1/Mar/1963 } \\
\text { 30/Jun/1999 } \\
53053\end{array}$ \\
\hline 9 & $\begin{array}{l}\text { Novolaza- } \\
\text { revskaya }\end{array}$ & $70.8^{\circ} \mathrm{S}$ & $11.8^{\circ} \mathrm{E}$ & 119 & $* \# \%$ & $\begin{array}{l}1 / \text { Feb/1961 } \\
31 / \text { Oct/2006 } \\
64000\end{array}$ & $\begin{array}{l}1 / \text { Feb/1961 } \\
31 / \text { Oct/2006 } \\
64000\end{array}$ & $\begin{array}{l}\text { 1/Feb/1961 } \\
31 / \text { Oct/2006 } \\
64000\end{array}$ \\
\hline 10 & Syowa & $69.0^{\circ} \mathrm{S}$ & $39.6^{\circ} \mathrm{E}$ & 21 & $\% \$$ & $\begin{array}{l}\text { Feb/13/1957 } \\
\text { Jan/01/2005 } \\
62779\end{array}$ & $\begin{array}{l}\text { Feb/09/1957 } \\
\text { Jan/01/2005 } \\
62795\end{array}$ & $\begin{array}{l}\text { Feb/10/1957 } \\
\text { Jan/01/2005 } \\
62788\end{array}$ \\
\hline
\end{tabular}

\subsection{Comparison methods}

Data from the reanalysis were interpolated onto the station location using bilinear interpolation. The evaluation started with the computation of standard statistics, including correlation, bias, and root-meansquare error (RMSE). Here, bias is defined as the difference between the mean observed value and the mean reanalysis value over a given period. RMSE refers to the square root of the mean-squared difference between the reanalysis values and the observed values. The statistical comparison was followed by comparisons of spectral properties. Power spectra were obtained from Fast Fourier transform (FFT) with the examination of the red noise spectrum. A 10-90-day band-pass filter was applied to the daily variables before the FFT in order to focus on the ability of the reanalysis data to capture intraseasonal variations. Finally EOF analyses were performed on the two reanalysis datasets to determine the differences in their spatial patterns of variability.

\section{Validation results}

\subsection{Comparisons with surface data}

\subsubsection{Annual cycle}

The comparison statistics of sea-level pressure over an annual cycle are shown in Fig. 2 for selected stations. At each station and for each month observations are correlated with the two reanalysis. The ERA-40 results closely track the observed annual variation, with correlation coefficients greater than 0.9 at nearly all the stations, except for Mirny and Novolazarevskaya where the correlation coefficients dropped to as low as 0.74. With 21 degrees of freedom, correlations exceeding $\pm 0.41, \pm 0.53$ are significant at the $95 \%$ and $99 \%$ 
levels. Compared to ERA-40, the correlation coefficients between the NCEP reanalysis and observations are somewhat lower, but still above 0.8 at most stations. The lowest correlations for the NCEP reanalysis data, at Casey, Davis, and Mirny, with the NCEP reanalysis data occurred in November. Detailed examinations revealed that low correlations at these three stations came mainly from the data between 1979 and 1983, which might be partially due to problems with the simulation of low pressure troughs or springtime sea ice and needs to be explored further. The above findings do not agree with the results of Bromwich and Fogt (2004), who found a seasonal dependence and lowest correlations in winter. A possible reason is that the time series of the present data are different from those of Bromwich and Fogt (2004). The latter ranged from 1958 to 2001, which included the period before the modern satellite era (1979), when wintertime observational data are rare, and smaller correlations in winter are apparent. In the present study, the two reanalysis datasets are used from 1979 to 2001, after the advent of the modern satellite era, and thus the correlation in winter was greater. The seasonal correlation difference is also different from that of Bromwich and Fogt (2004). With more observational and satellite data assimilated in the reanalysis, the correlations between them and observations and renanlyses increase significantly.

The biases (Fig. 2c and $2 \mathrm{~d}$ ) in both the reanalysis are mostly negative, indicating that the surface pressure values in the reanalysis are generally overestimated. At some stations, the biases exhibited little monthly or seasonal variation, while at other stations they are somewhat higher during the cold season than compared to the warm season. At all stations, the biases are larger in the NCEP data than in ERA-40, with monthly mean bias values ranging from $+0.5 \mathrm{hPa}$ to $-4.8 \mathrm{hPa}$ in ERA-40, but from +0.6 to -7.3 in the NCEP reanalysis. Similar behavior is found in the distribution of RMSE, with higher values in the cold season and in the NCEP reanalysis.

All told, the statistics shown in Fig. 2 suggest a favor toward ERA-40 over NCEP. For ERA-40, Mirny and Novolazarevskaya provided the worst performance in all the calculated statistical measures. For NCEP, Casey and Mawson are outperformed by other stations. These four stations are all located in East Antarctica and their inferior performance may be due to the influence of katabatic wind induced by steep topography (Bromwich et al., 1999).

Similar to Fig. 2, Fig. 3 shows the statistics for 2-m air temperature over an annual cycle. Unlike surface pressure, the surface temperature biases in both reanalysis are consistently positive over the annual cycle for all but one station. The magnitudes of the biases vary substantially among the stations. In ERA-40, the values range from near zero at Farady and Bellingshausen to more than $10^{\circ} \mathrm{C}$ at Mawson and Novplazarevskaya. Similar distributions among the stations are found in the NCEP data, although the biases are significantly smaller at Mawson and Novplazarevskaya and slightly larger at other stations in NCEP compared to ERA-40. At most stations, the bias appears to have double peaks: one in spring (September-November) and another in the fall (February-April). Connolley and Harangozo (2001) also found large biases between observed near-surface temperatures and those from both the NCEP and ECMWF reanalysis datasets.

Despite the large biases, the correlation coefficients are high (the correlation coefficients at 95\%, 98\%, 99\% and $99.9 \%$ confidence levels are $0.41,0.48,0.53$ and 0.64, respectively, with 21 degrees of freedom.) indicating that the reanalysis data closely match observed variations. At all but two stations (Faraday and Novplazarevskaya), the correlation coefficients are above 0.8. At Faraday and Novplazarevskaya, the correlation coefficients drop to 0.7 for ERA-40, and to below 0.4 for NCEP.

In ERA-40 reanalysis data, biases and RMSEs are above $8^{\circ} \mathrm{C}$ at Mawson and Novplazarevskaya, and close to $0^{\circ} \mathrm{C}$ at Faraday and Bellingshausen. In comparison, in the NCEP data, the biases and RMSEs at these stations are below $10^{\circ} \mathrm{C}$ The deviations at West Antarctic stations (Bellingshausen and Faraday) are less than those at East Antarctic stations (Casey, Davis, Mawson, Mirny, and Novolazarevskaya). The reanalysis showed a tendency to reproduce colder temperatures tendency than observed. The colder 2-m air temperature in the two reanalysis corresponds corresponds with the higher surface pressure. Although the deviation of $2-\mathrm{m}$ air temperature in the NCEP data at Novolazarevskaya is larger than that in ERA-40, the deviations at other stations in the NCEP data are closer to those in ERA-40.

Compared to surface pressure and temperature, 10$\mathrm{m}$ wind speeds from the two reanalysis datasets are in poorer agreement with observations, as shown by lower correlations and larger biases and RMSEs (Fig. 4). The large positive biases indicate that the wind speeds in the reanalysis are much stronger than the observed, especially at Mawson and Novplazarevskaya, where the biases are $10-15 \mathrm{~m} \mathrm{~s}^{-1}$.

The wind speeds in the reanalysis are much less than observed. The biases and RMSEs of wind speeds in the NCEP data are smaller than those in ERA40. Results at Mawson and Novplazarevskaya are worse than at other stations. Figure 4 shows that 

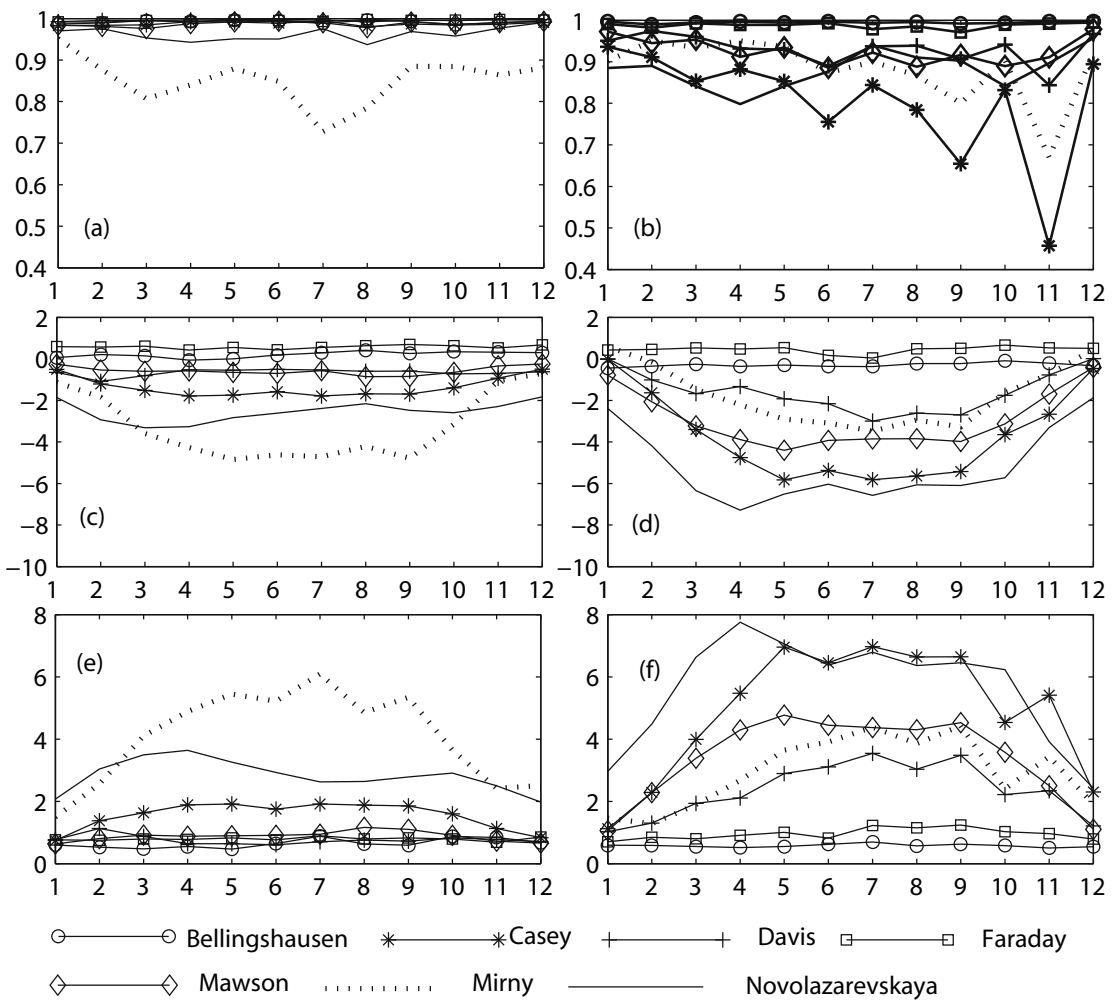

Fig. 2. Annual cycle of comparison between observed and reananlysis mean sea level pressure values (1979-2001) for (a), (c), (e) ERA-40 and (b), (d), (f) ECEP for stations with label * of Table 1. (a), (b) correlation; (c), (d) bias (hPa); and (e), (f) rmse $(\mathrm{hPa})$. The abscissa is month.
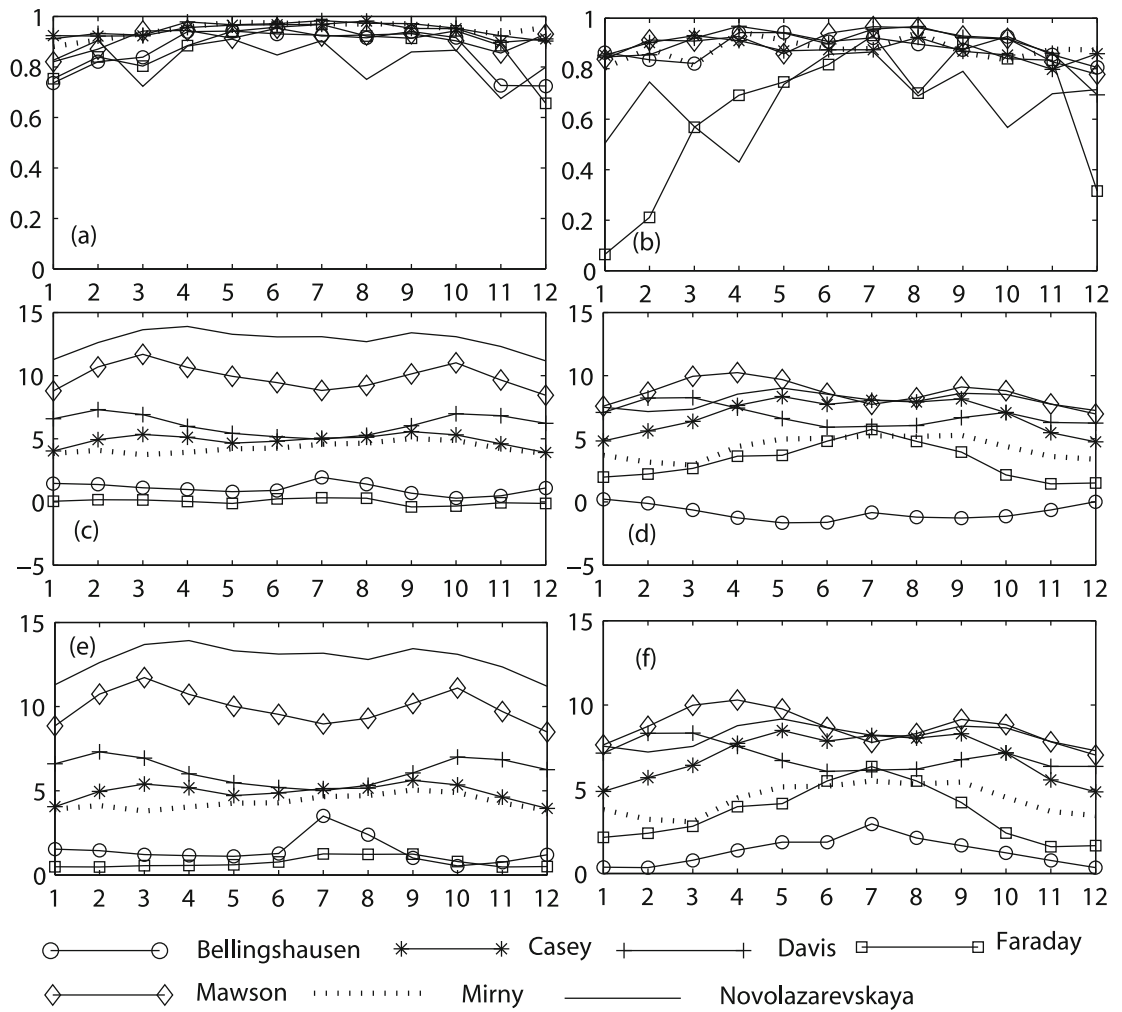

Fig. 3. Same as in Fig. 2, but for 2-m air temperature (the unit for temperature is ${ }^{\circ} \mathrm{C}$ ). 

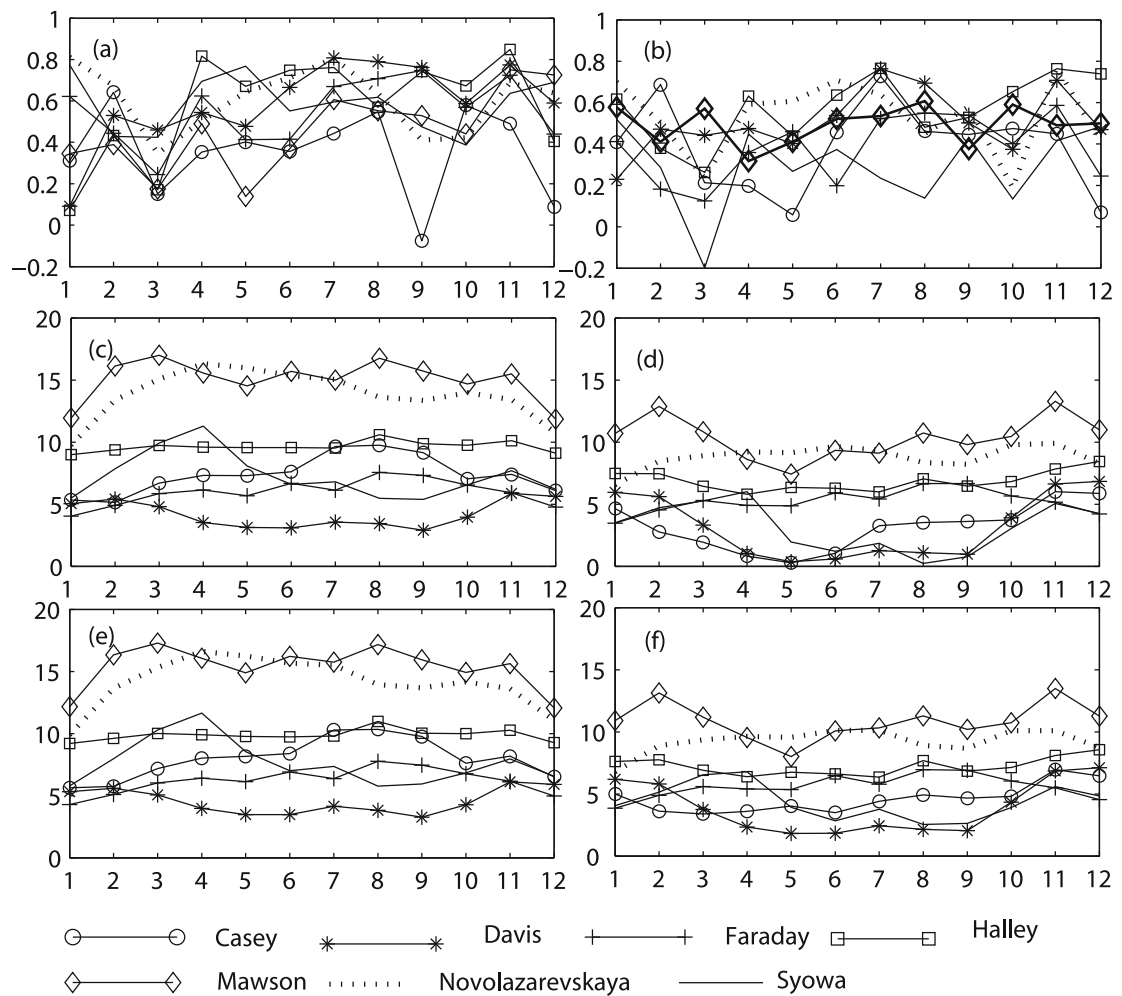

Fig. 4. Same as in Fig. 2, but for $10-\mathrm{m}$ wind velocity.
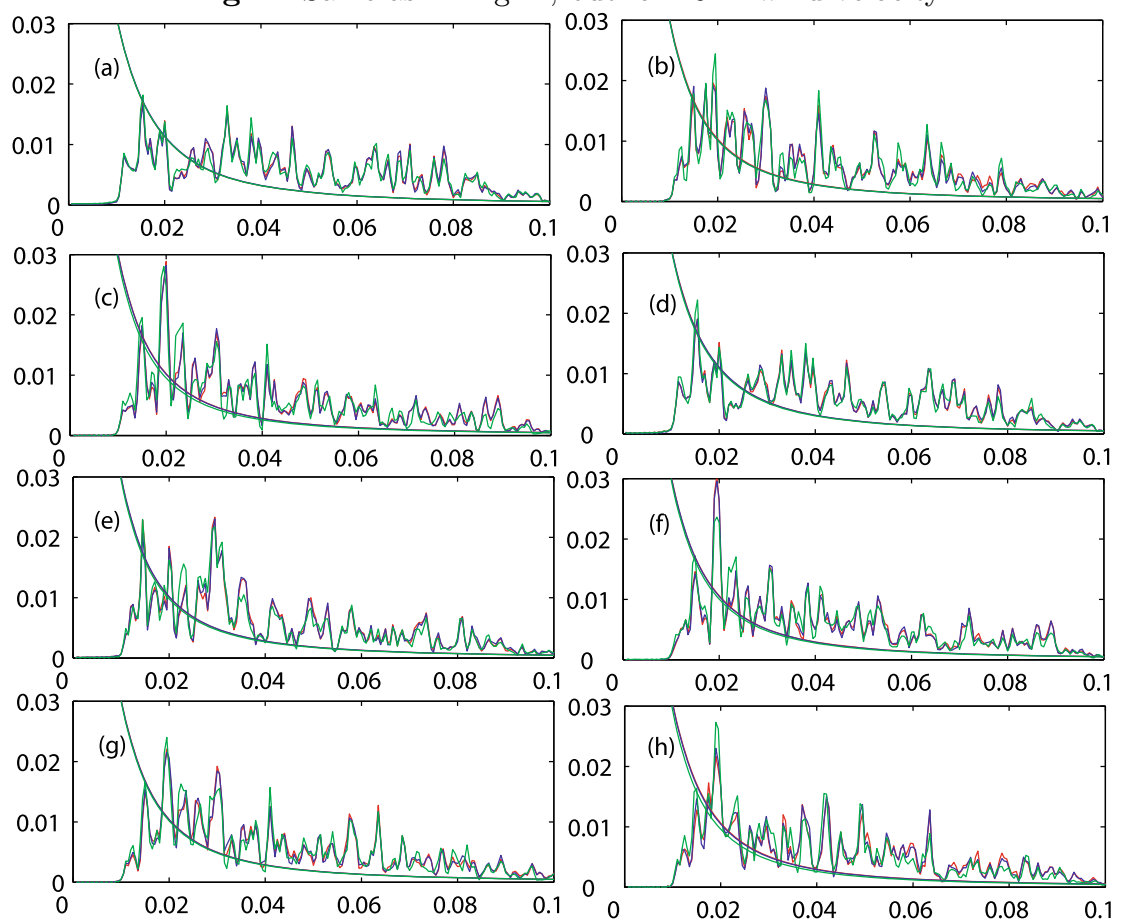

Fig. 5. Spectral density of surface pressure in NCEP, ERA-40, and observations at 8 stations. Red, blue and green line indicate the spectrum of observed data, ERA40 renanlyses data and NCEP reananlyses and their red noise with $95 \%$ confidence level, respectively. (a) Bellingshausen, (b) Casey, (c) Davis, (d) Faraday, (e) Halley, (f) Mawson, (g) Mirny, (h) Novolazarevskaya. The abscissa is frequency (cycle/day); the ordinate is spectral density. 
Table 2. Correlation coefficients of the time series of surface pressure (April to September) from 1979 to 2001 and their filtered spectral density for daily reanalysis (ERA-40 and NCEP) and observations.

\begin{tabular}{lcccc}
\hline Station name & $\begin{array}{c}\text { Unfiltered time } \\
\text { series in ERA-40 }\end{array}$ & $\begin{array}{c}\text { Filtered spectrum } \\
\text { in ERA-40 }\end{array}$ & $\begin{array}{c}\text { Unfiltered time } \\
\text { series in NCEP }\end{array}$ & $\begin{array}{c}\text { Filtered spectrum } \\
\text { in NCEP }\end{array}$ \\
\hline Bellingshausen & 0.94 & 0.998 & 0.78 & 0.987 \\
Casey & 0.90 & 0.997 & 0.71 & 0.978 \\
Davis & 0.93 & 0.999 & 0.69 & 0.968 \\
Faraday & 0.95 & 0.999 & 0.79 & 0.991 \\
Halley & 0.93 & 0.998 & 0.74 & 0.983 \\
Mawson & 0.93 & 0.998 & 0.75 & 0.976 \\
Mirny & 0.96 & 0.996 & 0.64 & 0.979 \\
Novolazarevskaya & 0.91 & 0.994 & 0.72 & 0.969 \\
\hline
\end{tabular}

the wind velocities in the reanalysis are not reliable in Antarctica, and thus wind data from the two reanalysis datasets should be used with caution when studying interannual variability.

In summary, the statistical comparisons of surface data suggest that: (1) ERA-40 is overall in better agreement with observations than NCEP; (2) the reanalysis are more reliable in West Antarctica than East Antarctica; (3) sea level pressure is more reliable than 2-m air temperature and 10-m wind, which agrees with the results of Cullather et al. (1997); and (4) 10-m winds in both reanalysis are poor representations of actual winds over Antarctica.

\subsubsection{Intraseasonal variation}

The above analyses focused on the annual cycle and interannual variation of each month. However, because of the larger amplitude and more significant periodic response (Hsu and Weng, 2002; Yasunari and Kodama, 1993), the ERA-40 and NCEP reanalysis datasets (April to September) are mainly validated on intraseasonal timescales (10-90 days) by means of spectrum analysis. The spectral density of surface pressure is presented in Fig. 5 for seven of the stations listed in Table 1, plus Halley station. The spectra of the ERA-40 and NCEP reanalysis coincided with each other and with those of the observations, including their red noise spectrum. All three spectra have oscil- lations with periods between 10 and 50 days. Despite the similarity in spectral space, differences between the reanalysis and observations on the intraseasonal timescale are revealed by correlations between observations and the reanalysis (Table 2). The correlation coefficients are higher than 0.9 between ERA-40 and observations, but are lower then 0.8 between NCEP and observations. The correlation coefficients of filtered spectral values in ERA-40 are higher than in the NCEP data. Figure 6 also indicates that the 50-day period of $2-\mathrm{m}$ air temperature is not significant. Although some heights and locations of spectral peaks in ERA-40, and particularly in NCEP data, are different from those in the observations, the overall good agreement in the spectral peaks between the two reanalysis and the observations indicates that the two sets of reanalysis data captured the observed intraseasonal variation in surface temperature. To further confirm the difference in surface air temperature for the two reanalysis, the same correlation analyses for surface pressure are obtained, presented in Table 3 . The correlations in Table 3 are generally lower than those in Table 2, which suggests that the correlation significance of surface air temperature for the two reanalysis is worse than that of air pressure. However the performance of ERA-40 is better than that of NCEP, which is a similar result to the surface pressure comparison. Hence, the ERA-40 reanalysis data appear to be bet-

Table 3. Same as in Table 2, but for 2-m air temperature.

\begin{tabular}{lcccc}
\hline Station name & $\begin{array}{c}\text { Unfiltered time } \\
\text { series in ERA-40 }\end{array}$ & $\begin{array}{c}\text { Filtered spectrum } \\
\text { in ERA-40 }\end{array}$ & $\begin{array}{c}\text { Unfiltered time } \\
\text { series in NCEP }\end{array}$ & $\begin{array}{c}\text { Filtered spectrum } \\
\text { in NCEP }\end{array}$ \\
\hline Bellingshausen & 0.88 & 0.980 & 0.74 & 0.915 \\
Casey & 0.92 & 0.984 & 0.71 & 0.965 \\
Davis & 0.93 & 0.991 & 0.68 & 0.970 \\
Faraday & 0.90 & 0.968 & 0.58 & 0.942 \\
Halley & 0.85 & 0.976 & 0.51 & 0.921 \\
Mawson & 0.89 & 0.983 & 0.74 & 0.972 \\
Mirny & 0.93 & 0.987 & 0.71 & 0.975 \\
Novolazarevskaya & 0.84 & 0.959 & 0.70 & 0.942 \\
\hline
\end{tabular}



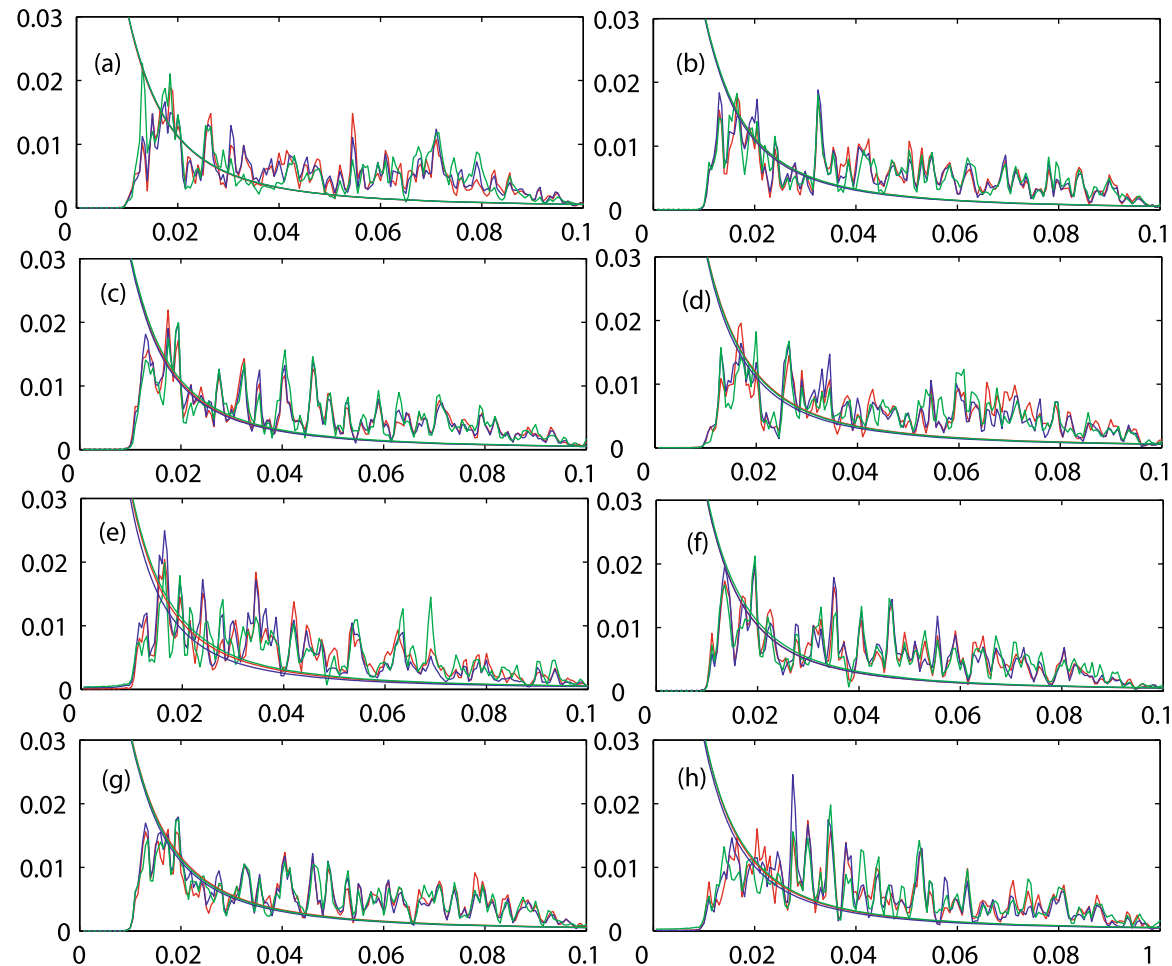

Fig. 6. Same as Fig. 5, but for 2-m air temperature.

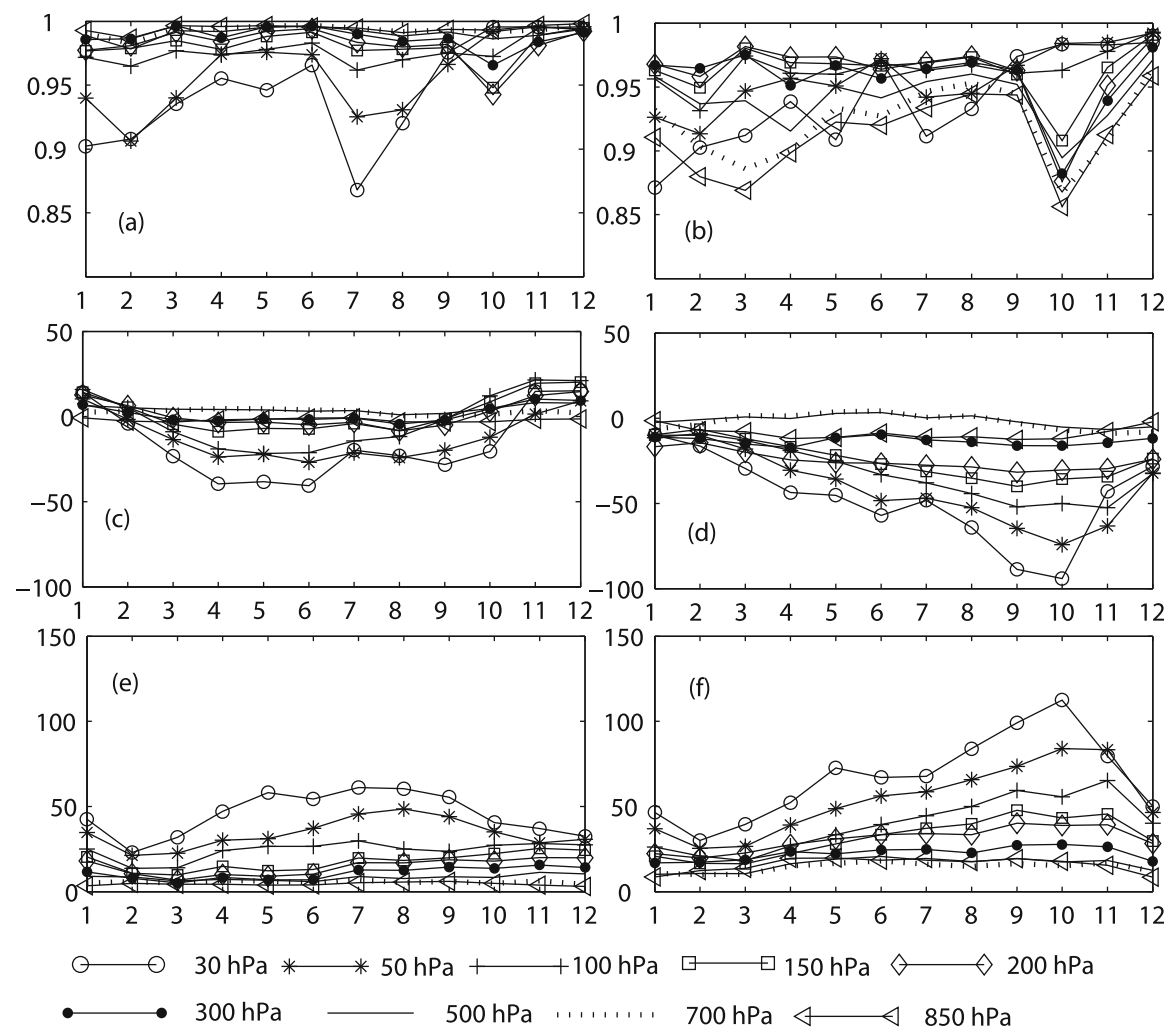

Fig. 7. Annual cycle of comparison between observed and reanalysis height values (1979-2001) for (a), (c), (e) ERA-40 and (b), (d), (f) NCEP for Syowa at nine levels $(30 \mathrm{hPa}, 50 \mathrm{hPa}, 100 \mathrm{hPa}, 150 \mathrm{hPa}, 200 \mathrm{hPa}, 300 \mathrm{hPa}, 500 \mathrm{hPa}, 700 \mathrm{hPa}, 850 \mathrm{hPa}$ ) (a), (b) correlation; (c), (d) bias (geopotential meter); and (e), (f) rmse (geopotential meter). The abscissa is month. 


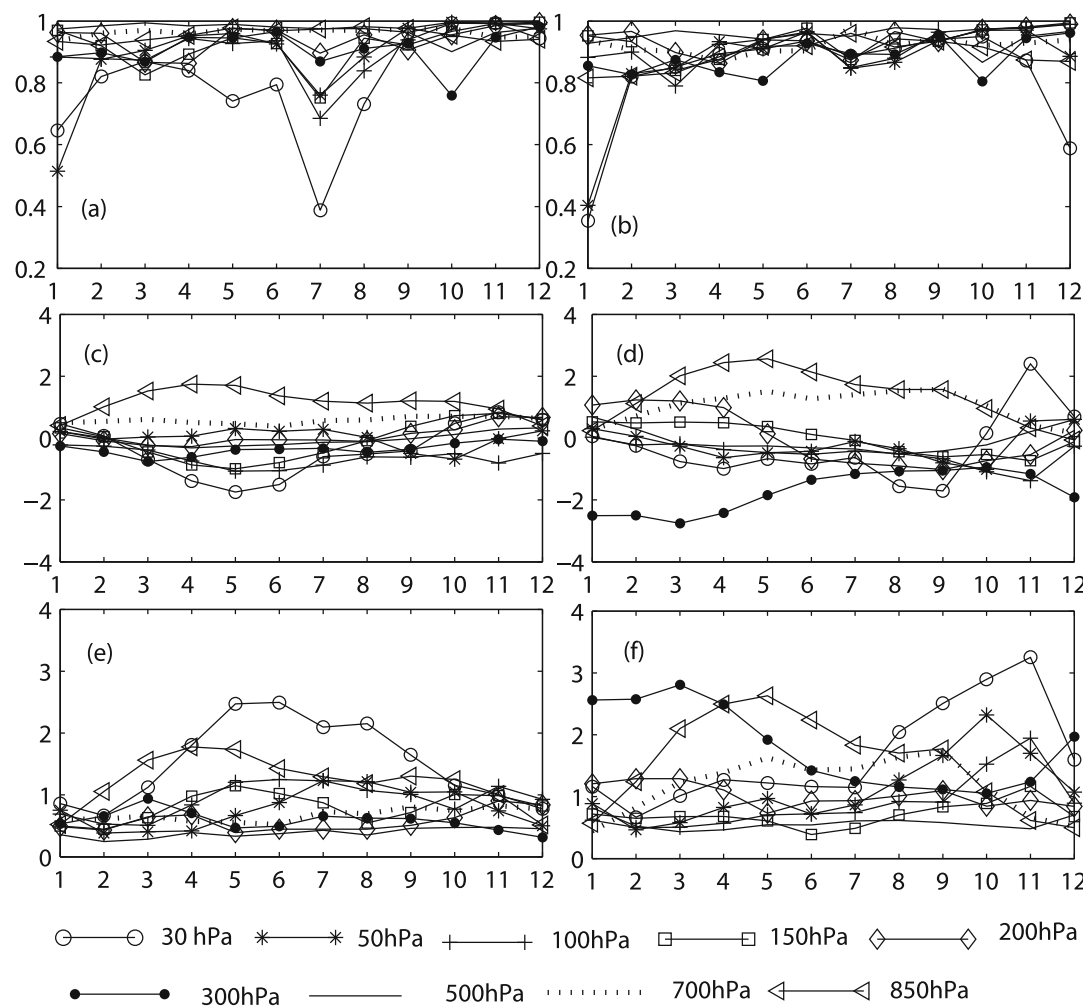

Fig. 8. Same as Fig. 7., but for air temperature.
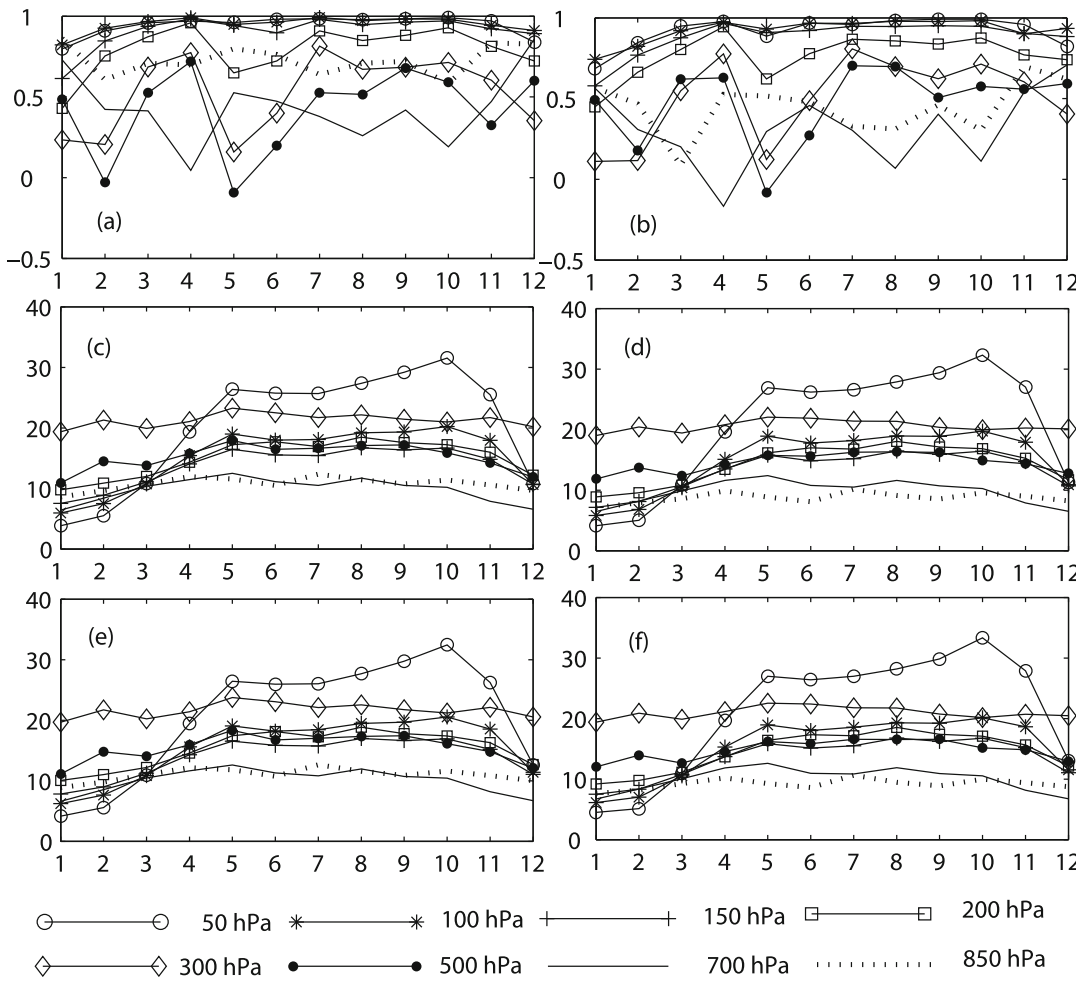

Fig. 9. Same as Fig. 7, but for wind velocity. 
ter than the NCEP reanalysis data for intraseasonal research in the Antarctic.

\subsection{Verification of upper-air data}

\subsubsection{Annual cycle}

Due to a lack of long-term, good quality data, the upper air comparison is limited to only one site, Syowa. Figure 7 shows the comparison statistics, including biases, standard deviations, and correlation coefficients, between the observed geopotential heights of nine standard pressure levels and those from ERA40 and NCEP data. At each level and month, correlation coefficeints can be calculated between observations and reanalysis data. Except for the two top levels (30 and $50 \mathrm{hPa}$ ), the correlation coefficients between the ERA-40 reanalysis and observations are higher $(>0.9)$ than those between the NCEP reanalysis and the observations. The bias and RMSE in ERA-40 exhibited a seasonal dependence, with larger values in winter than in summer. In the NCEP data, a larger bias and RMSE occur in spring. The larger deviation might be connected to the simulation of the polar vortex in spring; the strength of the polar vortex in the NCEP data is weaker than observed. The biases (the largest is approximately $100 \mathrm{~m}$ ) in the NCEP data are much greater than in ERA-40, where the largest is 50 $\mathrm{m}$. The biases and RMSE increase with height in both reanalysis.

Figure 8 shows the comparison statistics for temperature at nine standard pressure levels. The correlation coefficients are all over 0.8 except for the two highest levels (30-hPa and 50-hPa). For ERA-40, the biases and RMSEs are within $\pm 2{ }^{\circ} \mathrm{C}$, and positive at lower levels (850 and $700 \mathrm{hPa}$ ) and negative at $30 \mathrm{hPa}$. Similarly, the biases in the NCEP data are also generally within $\pm 2^{\circ} \mathrm{C}$, but the positive biases at 850 and $700 \mathrm{hPa}$ are slightly larger in the NCEP data than in ERA-40. The largest negative bias $\left(\sim 2.5^{\circ} \mathrm{C}\right)$ occurs at $300 \mathrm{hPa}$ in the NCEP data.

Similar to the surface comparison, the wind speeds at different heights in the reanalysis data showed poor agreement with observed wind speeds, compared to temperature and geopotential heights (Fig. 9). The differences between wind speeds in the ERA-40 and NCEP reanalysis in the upper level are quite small.

Wind velocities in both reanalysis datasets are well below those observed. The biases are generally between $8-15 \mathrm{~m} \mathrm{~s}^{-1}$ and the largest biases of over $20 \mathrm{~m}$ $\mathrm{s}^{-1}$ occurred at the 50- and $300-\mathrm{hPa}$ levels. To examine why the biases are much larger at these levels, Fig. 10 displays the climatological wind velocity in winter (June, July, August) and summer (December, January, and February). In winter the westerly circulation of the Antarctic polar vortex is strongest in the upper stratosphere (Mohanakumar, 2008; Fig. 6.15). Hence, the largest deviation in winter takes takes place at the $50-\mathrm{hPa}$ level. In summer, the largest wind velocity appears at the $300 \mathrm{hPa}$ level as a result of the collapse of the Antarctic polar vortex (Mohanakumar, 2008; Fig. 6.16), so the largest deviation in summer occurs at the $300 \mathrm{hPa}$ level.

Although the comparisons are made at only one upper-air station, the above results suggest that upper-level temperature and geopotential height fields are somewhat better in ERA-40 than in the NCEP reanalysis on an interannual timescale. The poor agreement between the reanalysis and observed wind suggests that the upper-level winds in both reanalysis should be used with caution, especially at $300-\mathrm{hPa}$ in summer and in the upper stratosphere in winter.

\subsubsection{Intraseasonal variation}

The performance of the two reanalysis in capturing intraseasonal variation at the upper levels is evaluated using daily air temperature and geopotential heights at four standard pressure levels $(100,300,500$, and 850 $\mathrm{hPa}$ ) from 1979 through 2001 (April to September) at three upper-air sites (Mirny, Syowa, Davis) in East Antarctica, and one site (Halley) in West Antarctica (Fig. 11 and Fig. 12). The same filter as described in section 3 is also applied. The correlation coefficients between ERA-40 data and observations and between NCEP data and observations of the non-filtered time series and their filtered spectral densities are shown in Table 4 for geopotential heights, and in Table 5 for temperature. The correlations of the non-filtered heights at four different levels are higher between
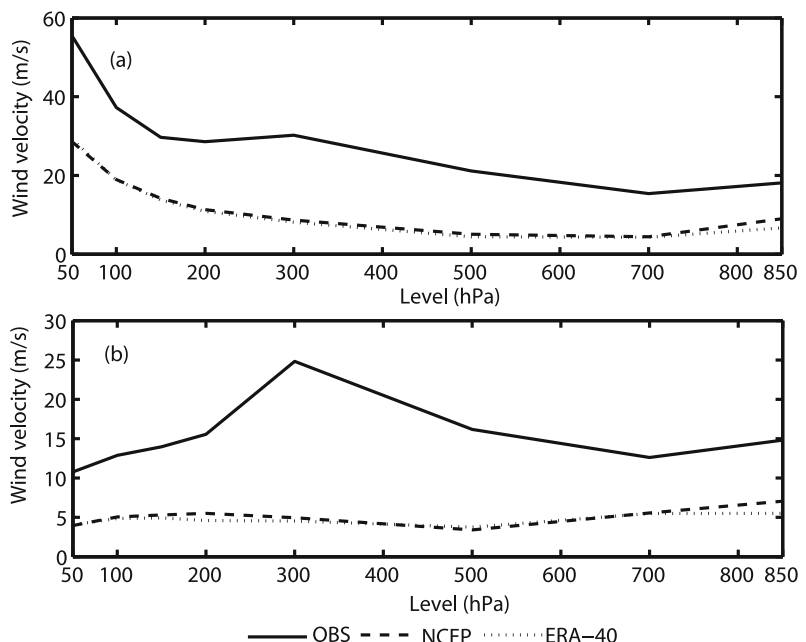

Fig. 10. The climatological wind velocity at 8 different levels (50 hPa, $100 \mathrm{hPa}, 150 \mathrm{hPa}, 200 \mathrm{hPa}, 300 \mathrm{hPa}, 500$ $\mathrm{hPa}, 700 \mathrm{hPa}, 850 \mathrm{hPa}$ ) (a) winter (June, July, August); (b) summer (December, January, and February). 
Table 4. Same as in Table 2, but for height at Davis, Halley, Mirny, and Syowa at 100-hPa, 300-hPa, 500-hPa, and 850-hPa levels.

\begin{tabular}{lcccc}
\hline Station name & $\begin{array}{c}\text { Unfiltered time } \\
\text { series in ERA-40 }\end{array}$ & $\begin{array}{c}\text { Filtered spectrum } \\
\text { in ERA-40 }\end{array}$ & $\begin{array}{c}\text { Unfiltered time } \\
\text { series in NCEP }\end{array}$ & $\begin{array}{c}\text { Filtered spectrum } \\
\text { in NCEP }\end{array}$ \\
\hline Davis 100-hPa & 0.993 & 0.9988 & 0.985 & 0.9982 \\
Davis 300-hPa & 0.980 & 0.9979 & 0.948 & 0.9936 \\
Davis 500-hPa & 0.976 & 0.9976 & 0.933 & 0.9906 \\
Davis 850-hPa & 0.962 & 0.9975 & 0.889 & 0.9832 \\
Halley 100-hPa & 0.979 & 0.9982 & 0.985 & 0.9966 \\
Halley 300-hPa & 0.904 & 0.9881 & 0.939 & 0.9819 \\
Halley 500-hPa & 0.895 & 0.9904 & 0.937 & 0.9824 \\
Halley 850-hPa & 0.882 & 0.9921 & 0.923 & 0.9790 \\
Mirny 100-hPa & 0.977 & 0.9944 & 0.971 & 0.9932 \\
Mirny 300-hPa & 0.961 & 0.9923 & 0.926 & 0.9904 \\
Mirny 500-hPa & 0.956 & 0.9898 & 0.919 & 0.9875 \\
Mirny 850-hPa & 0.925 & 0.9817 & 0.857 & 0.9753 \\
Syowa 100-hPa & 0.995 & 0.9996 & 0.990 & 0.9992 \\
Syowa 300-hPa & 0.988 & 0.9979 & 0.952 & 0.9933 \\
Syowa 500-hPa & 0.986 & 0.9973 & 0.943 & 0.9939 \\
Syowa 850-hPa & 0.976 & 0.9949 & 0.903 & 0.9885 \\
\hline
\end{tabular}

Table 5. Same as in Table 4, but for air temperature.

\begin{tabular}{lcccc}
\hline Station name & $\begin{array}{c}\text { Unfiltered time } \\
\text { series in ERA-40 }\end{array}$ & $\begin{array}{c}\text { Filtered spectrum } \\
\text { in ERA-40 }\end{array}$ & $\begin{array}{c}\text { Unfiltered time } \\
\text { series in NCEP }\end{array}$ & $\begin{array}{c}\text { Filtered spectrum } \\
\text { in NCEP }\end{array}$ \\
\hline Davis 100-hPa & 0.992 & 0.9986 & 0.987 & 0.9957 \\
Davis 300-hPa & 0.967 & 0.9916 & 0.889 & 0.9418 \\
Davis 500-hPa & 0.959 & 0.9960 & 0.905 & 0.9878 \\
Davis 850-hPa & 0.937 & 0.9864 & 0.889 & 0.9754 \\
Halley 100-hPa & 0.972 & 0.9988 & 0.988 & 0.9987 \\
Halley 300-hPa & 0.775 & 0.9414 & 0.856 & 0.9011 \\
Halley 500-hPa & 0.802 & 0.9597 & 0.888 & 0.9673 \\
Halley 850-hPa & 0.801 & 0.9721 & 0.791 & 0.9319 \\
Mirny 100-hPa & 0.981 & 0.9945 & 0.976 & 0.9943 \\
Mirny 300-hPa & 0.927 & 0.9842 & 0.846 & 0.9390 \\
Mirny 500-hPa & 0.942 & 0.9890 & 0.875 & 0.9878 \\
Mirny 850-hPa & 0.900 & 0.9816 & 0.845 & 0.9652 \\
Syowa 100-hPa & 0.992 & 0.9991 & 0.989 & 0.9984 \\
Syowa 300-hPa & 0.959 & 0.9925 & 0.881 & 0.9523 \\
Syowa 500-hPa & 0.963 & 0.9932 & 0.905 & 0.9872 \\
Syowa 850-hPa & 0.946 & 0.9859 & 0.895 & 0.9740 \\
\hline
\end{tabular}

ERA-40 and observations than between NCEP and observations at three East Antarctica stations, but the opposite occurs at the West Antarctica station (Halley). The correlation of spectral density of the geopotential heights in ERA-40 is better than that in the NCEP data. The correlation appears to increase with increasing height, which could be partially attributable to the decreased influence on height variation by surface forcing higher up in the atmosphere. This point is further illustrated by Fig. 11, as the three spectral density curves collapse at the $100 \mathrm{hPa}$ level, and the number of spectral peaks is smaller. The temperature correlations between ERA-40 and observations are larger than those for NCEP at the three
East Antarctic stations, but lower at Halley (Table 5). The trend of better correlation with increased elevation is less obvious for temperatures in Table 5 than for geopotential heights in Table 4, but the reduced number of spectral peaks can also be found at $100 \mathrm{hPa}$ in Table 5 as in Table 4 .

The above results suggest that both reanalysis datasets are able to capture the observed variations on intraseasonal timescales, although the NCEP data appears to be slightly better than ERA-40 in West Antarctica, while ERA40 is better in East Antarctica. More upper-air data are needed to confirm these preliminary results. 
(a) 0.1

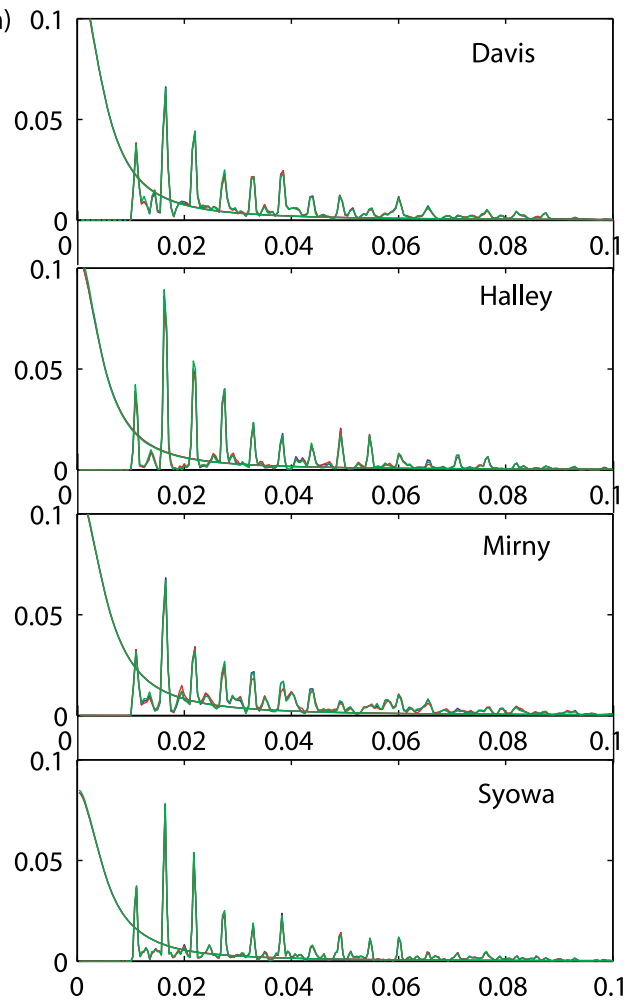

(c)

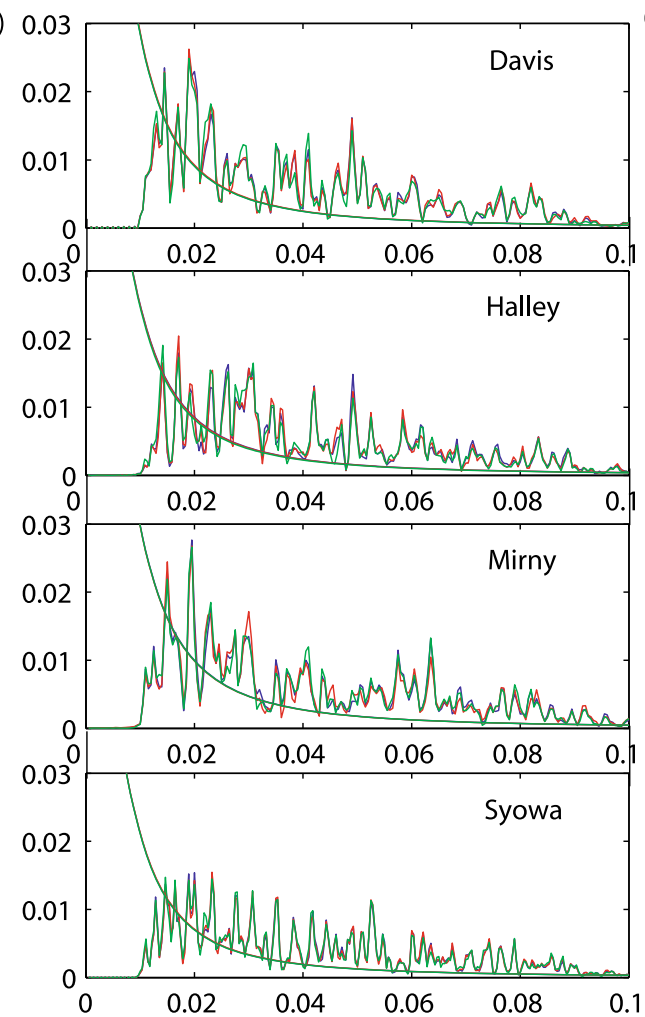

(b)

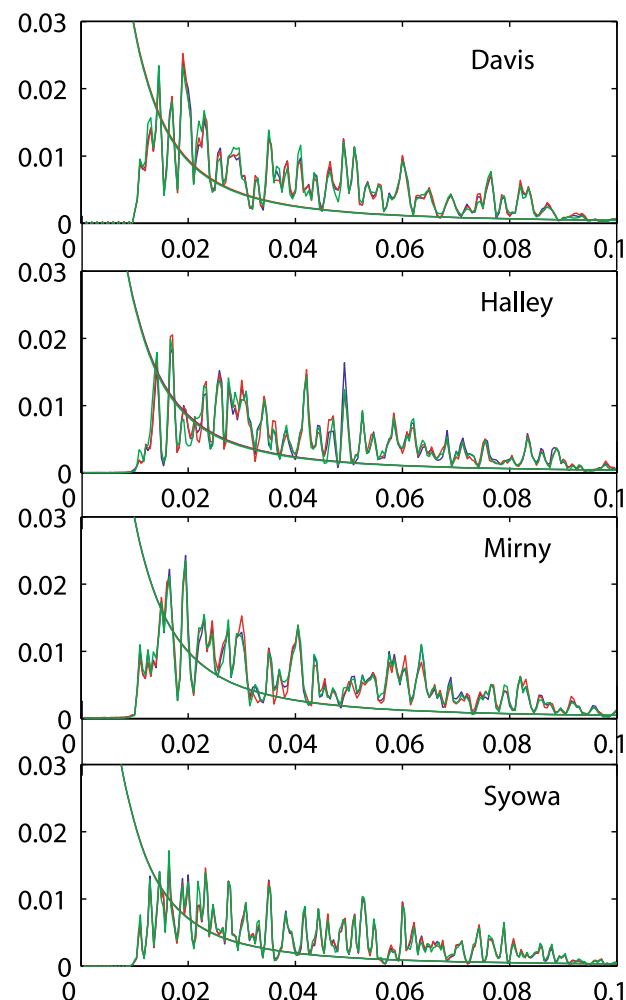

(d)

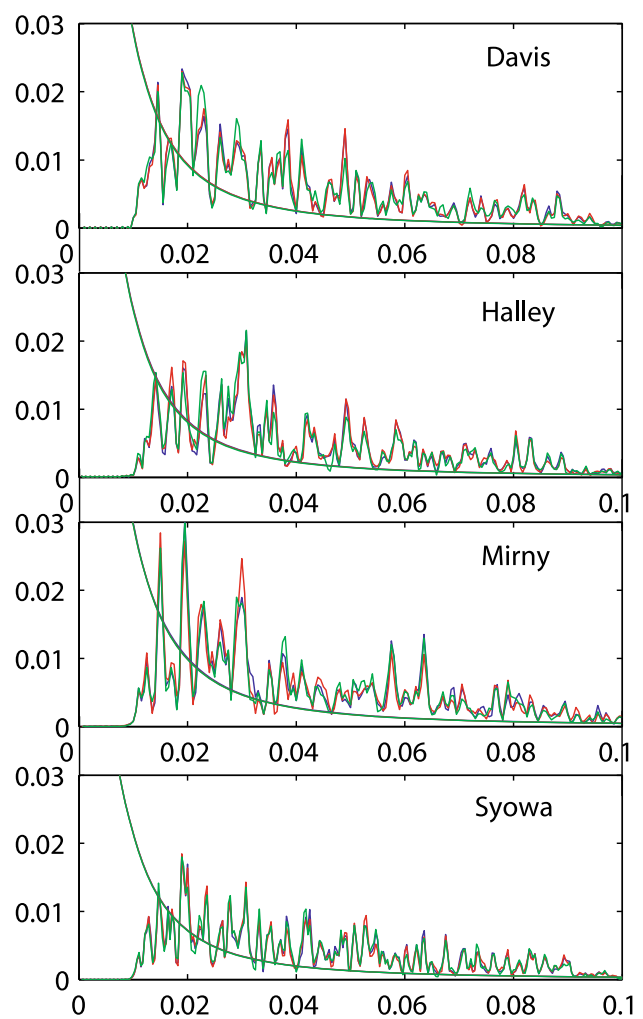

Fig. 11. Spectral density of daily height for NCEP (green lines), ERA-40 (blue lines), and observations (red lines) at four Antarctic stations (April to September) from 1979 to 2001 at (a) 100, (b) 300, (c) 500, and (d) $850 \mathrm{hPa}$. The abscissa is frequency (cycle/day); the ordinate is spectral density. 
(a)
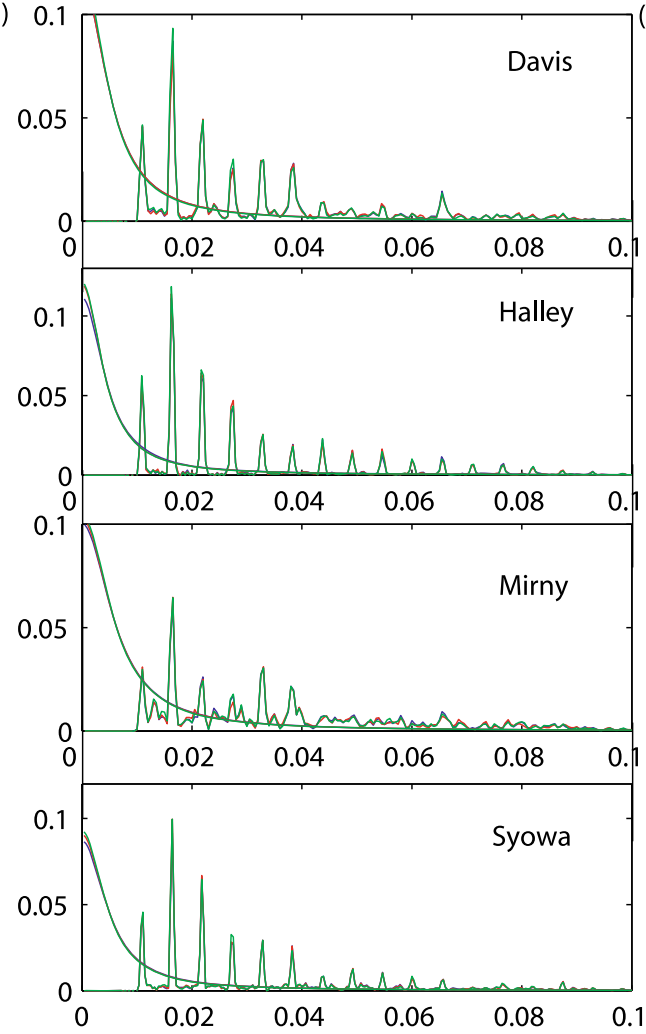

(c) 0.03

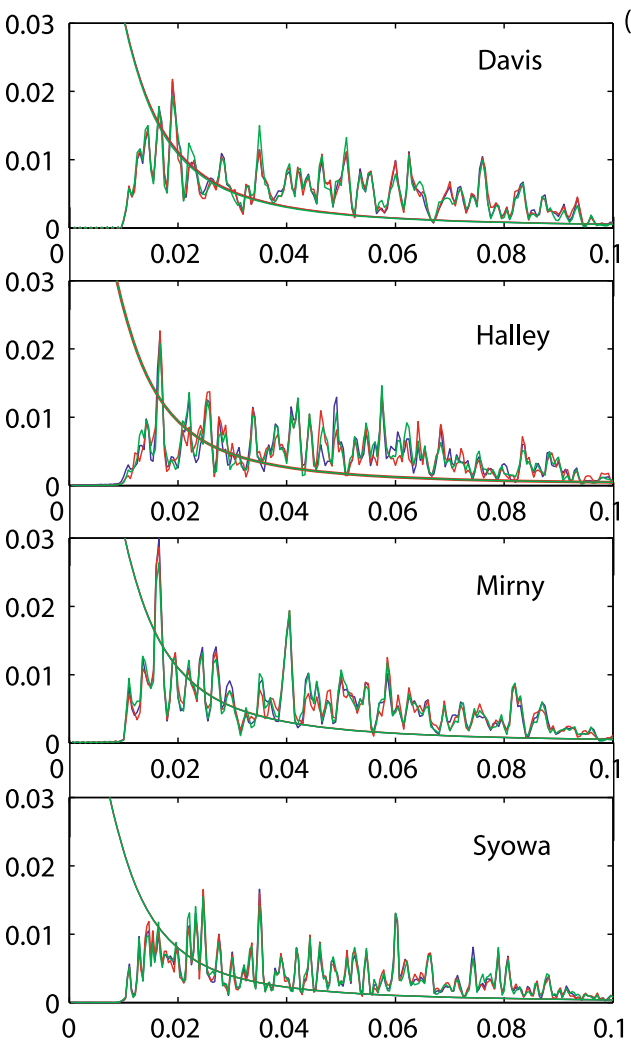

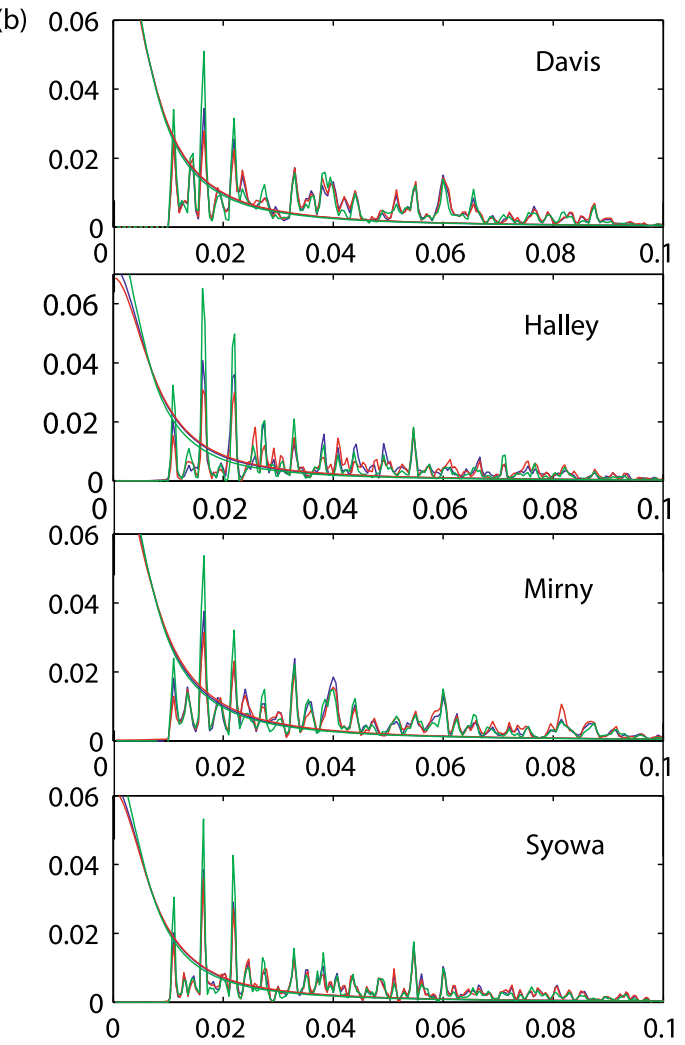

(d)

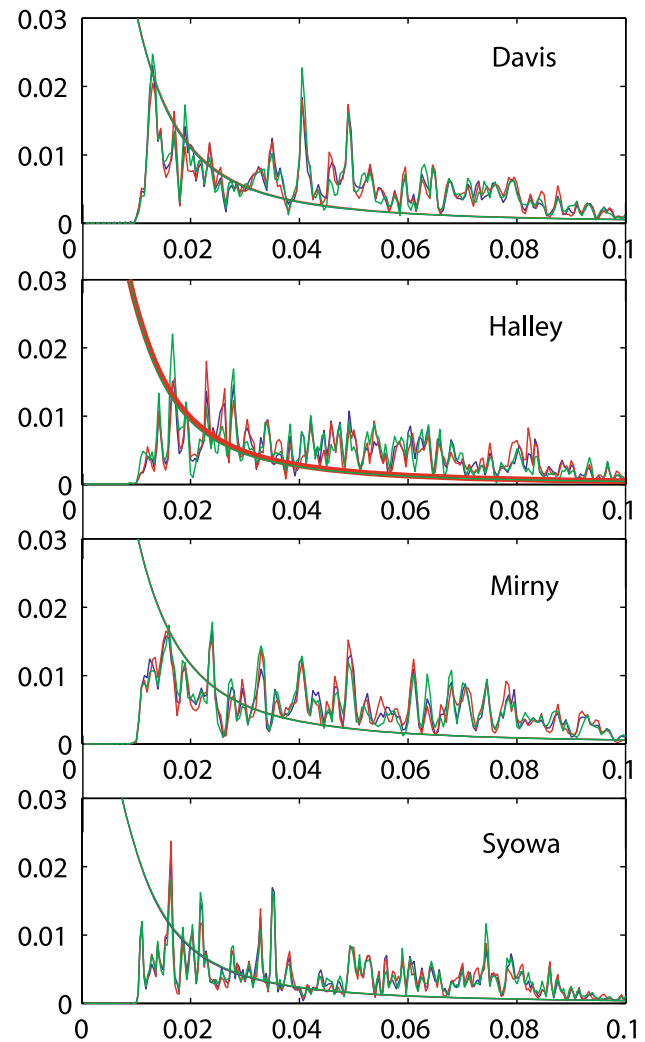

Fig. 12. Same as Fig. 11, but for air temperature. 


\section{Discussion}

It is import to note that the current comparisons are made only at a number of individual locations south of $60^{\circ} \mathrm{S}$, where long-term meteorological observations are available. Thus it is necessary to consider the performance of the two reanalysis datasets for the whole of the Antarctic continent. Therefore, climatological comparisons between ERA-40 and NCEP2 at sea level and 500-hPa levels are made in austral winter and the summer months. The average differences in winter and summer between sea level pressure in the NCEP and ERA-40 datasets in the Antarctic interior from 1979-2001 are found to be as large as 30 $\mathrm{hPa}$ (Figs. 13a and 13b). The difference at 500-hPa levels is $130 \mathrm{~m}$, which is larger than the Bromwich and Fogt (2004) result, who used data for all months from 1958-1978. King (2003) considered that the ECMWF operational analyses show close agreement with surface pressure observations in the Bellingshausen Sea region for February-May 2001. We also compare 2-m air temperature and 10-m wind fields during austral winter and summer (Fig. 14). During winter the surface air temperature in ERA-40 data is warmer than that in NCEP data; on the contrary, the summertime case is a reversal of this result. During two seasons the northerly anomaly exits over the Ross Sea, and the cyclone circulation appeared over the continent near $0^{\circ}$ longitude. The Antarctic Oscillation (AAO) index between the two reanalysis datasets is also compared. The AAO is defined as the first mode of EOF analysis of 700-hPa height from 1979 to 2001. The first mode pattern is shown in Fig. 14. These patterns are similar to each other, with a correlation coefficient of 0.997 and their time coefficients are found to be significantly correlated, with a correlation coefficient of 0.985 .

On intraseasonal timescales, EOF analysis is used to verify the consistency of the spatial distribution of sea level pressure in NCEP and ERA-40 (April to September) data from 1979 to 2001. The spatial patterns of the three leading modes in the NCEP data are similar to those in ERA-40, with correlation coefficients of $0.94,-0.91$, and -0.71 (1870 degrees of freedom), respectively (Fig. 15). However, the strengths and locations of the variance in Mode 3 for NCEP are not entirely in agreement with those for ERA-40. Three leading modes account for $35.5 \%, 9.2 \%$, and $8.2 \%$ of the intraseasonal variance in NCEP data, and $38.8 \%, 10.0 \%$, and $7.8 \%$ in ERA-40. The differences in percentage are rather small. The correlation coefficients of time coefficients of the three leading modes between NCEP and ERA-40 data are 0.84, -0.73, and -0.46 , with 4207 degrees of freedom. The differences in the main modes of sea level pressure between
NCEP and ERA-40 data on intraseasonal timescales are found to be negligible.

\section{Conclusions}

In this study, detailed comparisons between the NCEP and ERA-40 reanalysis datasets and observations made at several surface and upper atmosphere sounding stations in Antarctica on intraseasonal and interannual timescales have been performed. On an interannual timescale, the two reanalysis datasets showed good agreement with observations for sea-level pressure and upper-level temperature, as well as pressure throughout the troposphere. The two reanalysis datasets, however, showed relatively poor ability in capturing the variation of 2-m air temperature and wind speed at all levels, despite the fact that many observations and satellite datasets have been assimilated into the reanalysis since 1979 . On the intraseasonal timescale from April through September, both reanalysis datasets shows considerable ability in describing the observed variability.

In spite of the differences between the two reanalysis at levels higher than $30 \mathrm{hPa}$ in the Antarctic interior, for the above-mentioned stations they did show considerable ability in describing sea-level pressure. In summer, the ERA-40 and NCEP datasets performed with much greater ability, comparable to the ability in winter except for correlation in the NCEP data. ERA-40 is found to be closer to observations than the NCEP dataset for sea level pressure. The correlation with observations of 2-m temperature for ERA-40 is more significant than that for NCEP data, but the bias was smaller in the latter. The wind field needs to be improved in both reanalysis reanalysis datasets. The limited comparisons of the three variables suggest that the two reanalysis datasets are generally in better agreement with data taken in West Antarctica than East Antarctica, although more data are needed, especially from West Antarctica, to verify this.

On an interannual timescale, ERA-40 shows better agreement than the NCEP dataset with observations, and for both reanalysis the performance in the troposphere is better than that in the stratosphere. The largest bias in wind speed is found at the strong wind levels, independent of season.

Finally, the comparisons indicate that the two reanalysis datasets are able to capture observed intraseasonal variability. However, the current analysis of intraseasonal variability, which was performed for April through September, needs to be extended to other months. Based on the reliability of NCEP reanalysis data in Austral winter on the intraseasonal timescales, it is planned to use the two reanalysis datasets after 

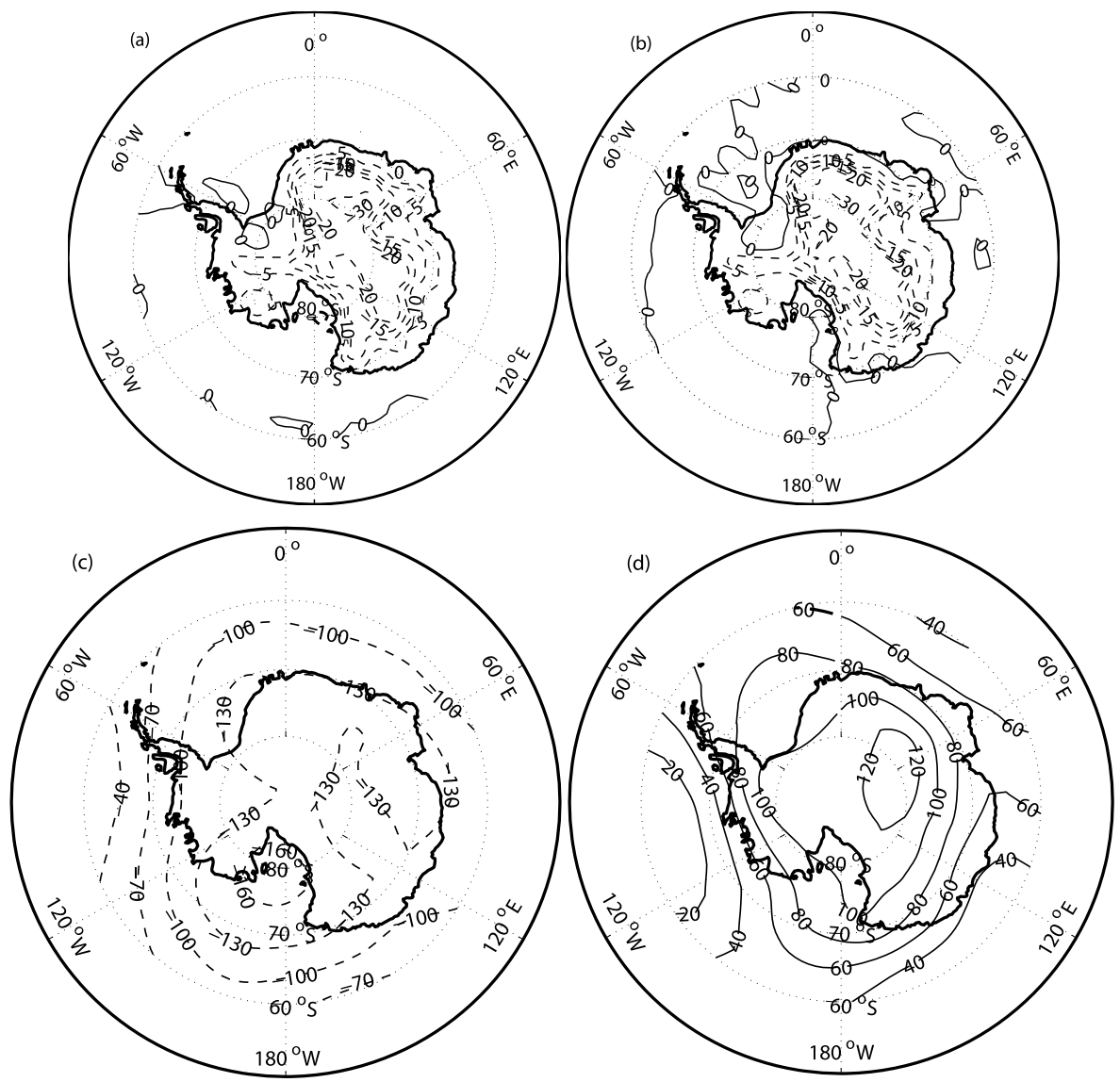

Fig. 13. The climatological ERA-40 minus NCEP sea level pressure (a), (b) and 500-hPa height (c), (d) difference for winter (June, July, and August) and summer (January, February, and December) (1979-2001) (a), (c) summer; (b), (d) winter. Units of sea level pressure and 500-hPa height are $\mathrm{hPa}$ and geopotential meter.

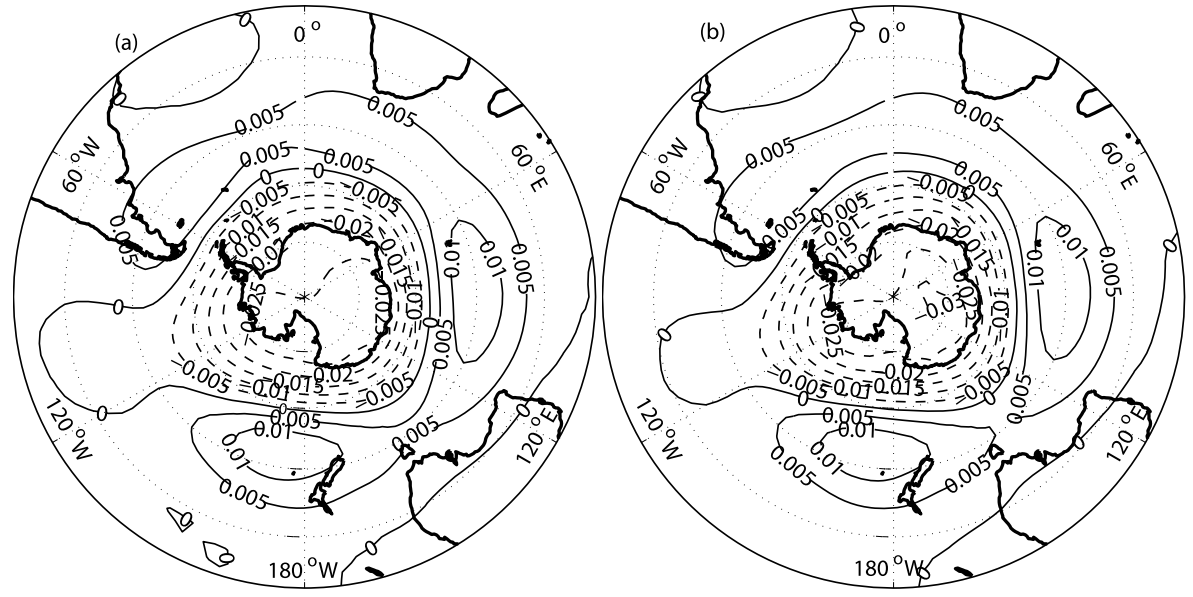

Fig. 14. The first mode pattern of EOF analysis of the 700-hPa geophysical height (a) for NCEP; (b) for ERA-40. 

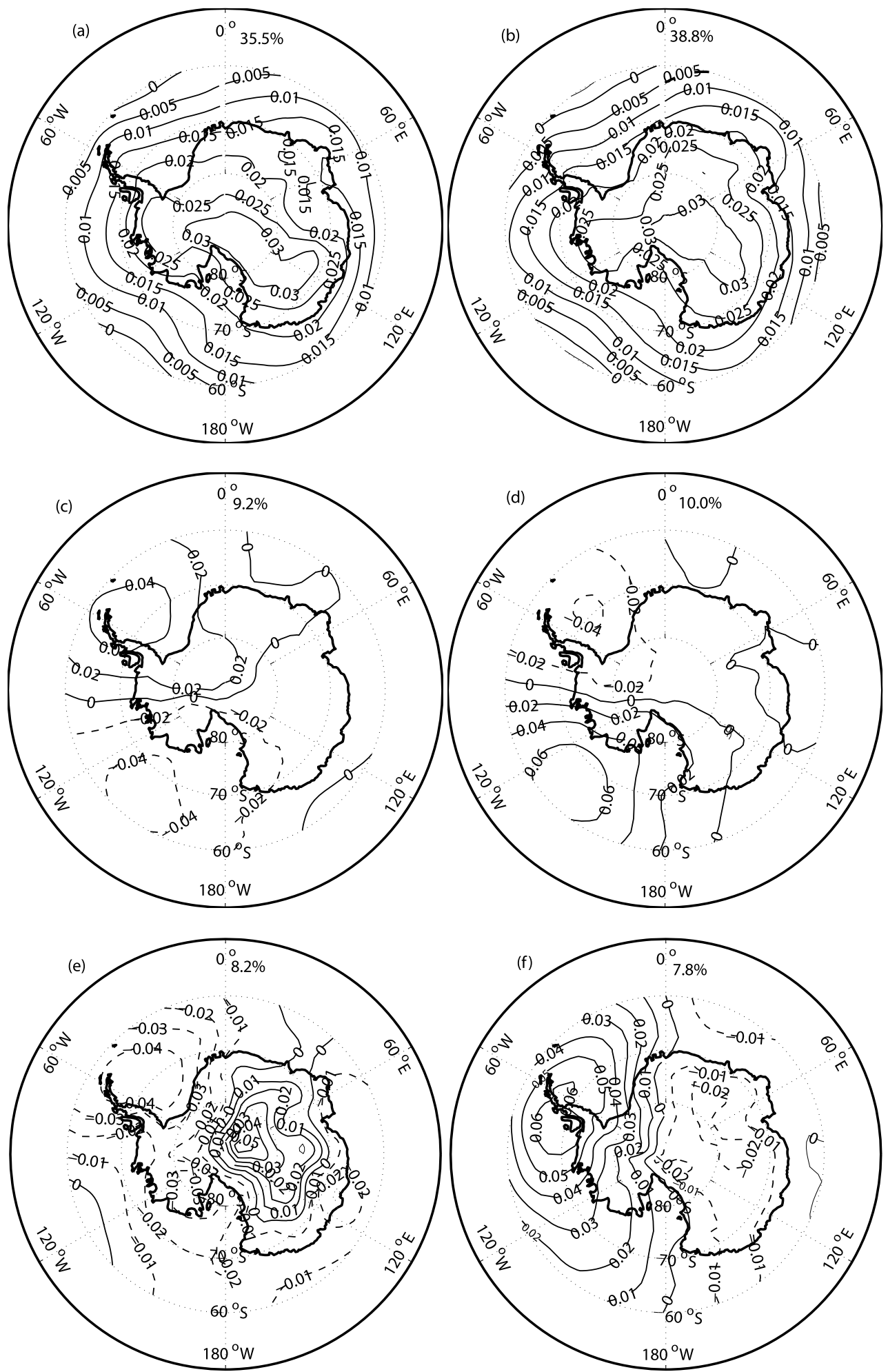

Fig. 15. The three leading EOFs of the intraseasonal (10-90 day) sea level pressure variance. (a), (c), (e) for NCEP; (b), (d), (f) for ERA-40. (a), (b) for Mode 1; (c), (d) for Mode 2 ; (e), (f) for Mode 3. 
1979 to study the intraseasonal variation in Antarctic winter.

Acknowledgements. NCEP/DOE 2 Reanalysis data was provided by NOAA/OAR/ESRL PSD, Boulder, Colorado, USA, from their website at http://www.cdc.noaa.gov/. This research was partially funded by the Chinese Polar Program Strategic Research Fund (No. 20080218), the National Natural Science Foundation of China (40233032-40640420556), and MOST (2006BAB18B03 and 2006BAB18B05). Two of the coauthors are from the National Center for Atmospheric Research, which is sponsored by the US National Science Foundation.

\section{REFERENCES}

Bromwich, D. H., and S. R. Smith, 1993: U. S. FROST: Data and Science Plan. Report from the U. S. FROST Workshop, BPRC Report No.7, 40pp.

Bromwich, D. H., and R. L. Fogt, 2004: Strong trends in the skill of the ERA-40 and NCEP-NCAR reanalysis in the high and midlatitudes of the Southern Hemisphere, 1958-2001. J. Climate, 17, 4603-4619.

Bromwich, D. H., F. M. Robasky, R. I. Cullather, and M. L. Van Woert, 1995: The atmospheric hydrologic cycle over the Southern Ocean and Antarctica from operational numerical analyses. Mon. Wea. Rev., 123, 3518-3538.

Bromwich, D. H., R. I. Cullather, and R. W. Grumbine, 1999: An assessment of the NCEP operational global spectral model forecasts and analyses for Antarctica during FROST. Wea. Forecasting, 14, 835-850.

Connolley, W. M., and S. A. Harangozo, 2001: A comparison of five numerical weather prediction analysis climatologies in southern high latitudes. J. Climate, 14, 30-44.

Cullather, R. I., D. H. Bromwich, and R. W. Grumbine, 1997: Validation of operational numerical analyses in Antarctic latitudes. J. Geophys. Res., 102, 1376113784 .

Fan, K., and H. J. Wang, 2004: Antarctic oscillation and the dust weather frequency in North China. Geophys. Res. Lett., 31, L10201.

Gibson, J. K., P. Kallberg, S. Uppala, A. Hernandez, A. Nomura, and E. Serrano, 1997: ERA Description. ECMWF Re-analysis Project Report Series No.1, 72pp.

Hines, K. M., D. H. Bromwich, and G. J. Marshall, 2000: Artificial surface pressure trends in the NCEPNCAR Reanalysis over the Southern Ocean and Antarctica. J. Climate, 13, 3940-3952.

Hsu, H. H., and S. P. Weng, 2002: Stratospheric Antarctic intraseasonal oscillation during the austral winter. $J$. Meteor. Soc. Japan, 80(4B), 1029-1050.

Jenne, R., 2000: Global observations for reanalysis, 1948- on. Proceedings of Second WCRP Int. Conf. on Reanalysis, Wokefield Park, United Kingdom, WMO, $5-8$.

Kalnay, E., and Coauthors, 1996: The NCEP/NCAR 40Year Reanalysis Project. Bull. Amer. Meteor. Soc. 77, 437-441.

Kallberg, P., A. Simmons, S. Uppala, and M. Fuentes, 2004: The ERA-40 archive. ERA-40 Project Report Series No.17, 3-4.

Kanamitsu, M., W. Ebisuzaki, J. Woollen, S. K. Yang, J. J. Hnilo, M. Fiorino, and G. L. Potter, 2002: NCEPDEO AMIP-II Reanalysis (R-2). Bull. Amer. Meteor. Soc., 83, 1631-1643.

King, J. C., 2003: Validation of ECMWF sea level pressure analyses over the Bellingshausen Sea, Antarctica. Wea. Forecasting, 18, 536-540.

Kistler, R., and E. Kalnay, 2000: The NCEP/NCAR reanalysis prior to 1958. Proceedings of Second ECRP Int. Conf. on Reanalysis, Wokefield Park, United Kingdom, WMO, 27-35.

Kistler, R., and Coauthors, 2001: The NCEP-NCAR 50Year Reanalysis: Monthly means CD-ROM and documentation. Bull. Amer. Meteor. Soc., 82, 247-267.

Marshall, G. J., 2002: Trends in Antarctic geopotential height and temperature: A comparison between radiosonde and NCEP-NCAR reanalysis data. J. Climate, 15, 659-674.

Mohanakumar, K., 2008: Stratospheric ozone depletion and Antarctic ozone hole. Stratosphere Troposphere Interactions: An Introduction, K. Mohanakumar, Ed., Springer Press, 276-277.

Sun, J. Q., H. J. Wang, and W. Yuan, 2008: A possible mechanism for the co-variability of the boreal spring Antarctic Oscillation and the Yangtze River valley summer rainfall. International Journal of Climatology, doi: 10.1002/joc.1773.

Turner, J., and Coauthors, 1996: The Antarctic First Regional Observing Study of the Troposphere (FROST) Project. Bull. Amer. Meteor. Soc., 77, 2007-2032.

Turner, J., S. Leonard, G. J. Marshall, M. Pook, L. Cowled, R. Jardine, S. Pendlebury, and N. Adams, 1999: An assessment of operational Antarctic analyses based on data from the FROST project. Wea. Forecasting, 14, 817-834.

Uppala, S. M., and Coauthors, 2005: The ERA-40 reanalysis. Quart. J. Roy. Meteor. Soc., 131, 2961-3012.

Yasunari, T., and S. Kodama, 1993: Intraseasonal variability of katabatic wind over East Antarctica and planetary flow regime in the Southern Hemisphere. J. Geophys. Res., 98(D7), 13063-13070.

Yue, X., and H. J. Wang, 2008: The springtime north Asia cyclone acticity index and the Southern Annular Mode. Adv. Atmos. Sci., 25(4), 673-679.

Zhu, Y. L., 2009: The Antarctic Oscillation-East Asian summer monsoon connections in NCEP-1 and ERA-40. Adv. Atmos. Sci., 26(4), 707-716, doi: 10.1007/s00376-009-8196-2. 